6

\title{
Enterococcus faecalis antagonizes Pseudomonas aeruginosa growth in
}

\section{polymicrobial biofilms}

Casandra Ai Zhu Tan¹, Ling Ning Lam², Goran Biukovic ${ }^{1}$, Eliza Ye-Chen Soh ${ }^{1}$, Xiao Wei Toh ${ }^{1}$, José A. Lemos ${ }^{2}$, Kimberly A. Kline ${ }^{1^{*}}$

${ }^{1}$ Singapore Centre for Environmental Life Sciences Engineering, School of Biological Sciences, Nanyang Technological University, Singapore

2Department of Oral Biology, University of Florida College of Dentistry, Gainesville, Florida, USA

${ }^{*}$ Corresponding author: Kimberly A. Kline

Email: kkline@ntu.edu.sg

Running title: $E$. faecalis antagonizes $P$. aeruginosa growth

Keywords: Enterococcus faecalis, Pseudomonas aeruginosa, polymicrobial interactions, mixed-species, lactate dehydrogenase (LDH), L-lactate, iron-restriction. 


\section{ABSTRACT}

Enterococcus faecalis is often co-isolated with Pseudomonas aeruginosa in polymicrobial biofilm-associated infections of wounds and the urinary tract. As a defense strategy, the host innately restricts iron availability at infection sites. Despite their co-prevalence, the polymicrobial interactions of these two pathogens in ironrestricted conditions, such as those found in the host, remains unexplored. Here we show that $E$. faecalis inhibits $P$. aeruginosa growth within biofilms when iron is restricted. E. faecalis lactate dehydrogenase (Idh1) gives rise to L-lactate production during fermentative growth. We find that $E$. faecalis $l d h 1$ mutant fails to inhibit $P$. aeruginosa growth. Additionally, we demonstrate that $I d h 1$ expression is induced in iron-restricted conditions, resulting in increased lactic acid exported and consequently, a reduction in $\mathrm{pH}$. Together, our results suggest that $E$. faecalis synergistically inhibit $P$. aeruginosa growth by decreasing environmental $\mathrm{pH}$ and L-lactate-mediated iron chelation. Overall, this study highlights that the microenvironment in which the infection occurs is important for understanding its pathophysiology.

\section{IMPORTANCE}

Many infections are polymicrobial and biofilm-associated in nature. Iron is essential for many metabolic processes and plays an important role in controlling infections, where the host restricts iron as a defense mechanism against invading pathogens. However, polymicrobial interactions between pathogens are underexplored in ironrestricted conditions. Here, we explore the polymicrobial interactions between commonly co-isolated $E$. faecalis and $P$. aeruginosa within biofilms. We find that $E$. faecalis modulates the microenvironment by exporting lactic acid which further chelates already limited iron, and also lowers the environmental $\mathrm{pH}$ to antagonize $P$. aeruginosa growth in iron-restricted conditions. Our findings provide insights into polymicrobial interactions between pathogens in an infection-relevant condition and how manipulating the microenvironment can be taken advantage of to better control infections. 


\section{INTRODUCTION}

61

Many infections are often polymicrobial in nature (1-3) and include wound infections (4-7), periodontitis $(8,9)$, otitis media $(10,11)$, urinary tract infections (UTI) $(12-15)$ and cystic fibrosis (16-20). Biofilms are also implicated in all these infections (21-37). Polymicrobial biofilms can better tolerate antibiotic treatment and escape from host immune responses, enabling the survival and persistence of the infecting bacteria (38, 39). Understanding how pathogens interact during infections may inform improved treatment strategies.

Iron is an essential nutrient for almost all microbial species. In humans, iron regulation functions as a host innate immune mechanism against invading pathogens (40). In the human body, iron is scarcely available to pathogens due to the sequestration of most iron intracellularly such that only a small amount of free iron (approximately $10^{-24} \mathrm{M}$ ) is accessible in the absence of infection (41). During an infection, additional ironwithholding mechanisms further restrict iron availability to pathogens (40). For example, immune cells producing hepcidin (42) or lactoferrin (43), and siderocalin/lipocalin-2 $(43,44)$ modulate iron availability at the infection site. As a result, when developing polymicrobial interaction models, it is critical to take into account the iron availability in the environment.

Enterococci are opportunistic pathogens implicated in several types of infections (45), and enterococcal infections in humans are mostly caused by Enterococcus faecalis and Enterococcus faecium $(46,47)$. E. faecalis is often isolated from infective endocarditis, UTI and mixed-species chronic wounds $(46,48,49)$. In addition to $E$. faecalis, infected wounds often contain other bacteria such as $P$. aeruginosa, $S$. aureus, Corynebacterium spp, Enterobacteriaceae spp, and Finegoldia magna (4, 48, 50-52). E. faecalis co-infection with $S$. aureus, $P$. aeruginosa and $F$. magna resulted in delayed wound closure and higher level of antimicrobial tolerance (52). During UTI, E. faecalis is also co-isolated with $P$. aeruginosa and Proteus mirabilis $(53,54)$. E. faecalis and $P$. aeruginosa co-infection during UTI resulted in more severe lesions in the kidneys and $P$. aeruginosa was more resistant to clearance by $\beta$-lactam antibiotics (53). While increasing efforts have been made to understand how interactions between pathogens can influence bacterial pathogenesis, few studies have explored 
94 the polymicrobial interactions in an infection-relevant, iron-restricted condition. Since

95 E. faecalis and $P$. aeruginosa are commonly co-isolated in different infection niches, 96 understanding the polymicrobial interactions between these two species is of interest

97 and clinical relevance. Further, there have been no reports examining the interaction

98 between these two species in iron-restricted conditions in any infection model.

99

100 In this work, we showed that $E$. faecalis inhibited $P$. aeruginosa growth within biofilms

101 when iron was restricted. The growth inhibition was a consequence of increased L-

102 lactate produced by $E$. faecalis, catalysed by lactate dehydrogenase (Idh1) from

103 pyruvate. We also showed that Idh1 expression was upregulated when iron was

104 restricted. L-lactate produced by $E$. faecalis was exported from the cell as lactic acid

105 (55), whereupon it was deprotonated to L-lactate releasing a hydrogen ion $\left(\mathrm{H}^{+}\right)$and in

106 turn lowering the $\mathrm{pH}$ in the surrounding environment. We demonstrated that this

107 lowered environmental $\mathrm{pH}$ and L-lactate-mediated chelation of iron ultimately

108 contributes to $P$. aeruginosa growth inhibition by $E$. faecalis in iron-restricted conditions. 


\section{RESULTS}

112 E. faecalis inhibits $\boldsymbol{P}$. aeruginosa growth in iron-restricted conditions. The

113 compound 2,2'-dipyridyl (22D) is widely used as a neutral ligand for the chelation of 114 metal ions and is a high affinity chelator of iron (56). Therefore, 22D was supplemented 115 into TSBG growth media to restrict iron availability. We first investigated the 116 interactions between 12 different $E$. faecalis clinical isolates and $P$. aeruginosa PAO1

117 BAA-47 using static biofilm assays. In iron-restricted media (TSBG supplemented with $1181 \mathrm{mM} 22 \mathrm{D}), \mathrm{PAO} 1 \mathrm{BAA}-47$ growth was inhibited in all of the mixed-species biofilms 119 compared to PAO1 BAA-47 single-species biofilm (Figure 1A). By contrast, E. faecalis 120 growth was similar in the single- and mixed-species biofilms (Figure 1B). These data 121 indicate that $E$. faecalis inhibition of $P$. aeruginosa is not strain specific. We next 122 performed the biofilm assay, now with $E$. faecalis OG1RF and eight different $P$. 123 aeruginosa clinical isolates, to examine whether $P$. aeruginosa susceptibility to $E$. 124 faecalis-mediated inhibition was strain specific. We observed that the growth of all $P$. aeruginosa isolates was inhibited in the mixed-species biofilms compared to their respective single-species counterpart (Figure 1C), while E. faecalis growth in the single- and mixed-species biofilms remained unaffected (Figure 1D). These data demonstrate that all tested $E$. faecalis and $P$. aeruginosa clinical isolates engage in mixed-species antagonism in iron-restricted conditions.

131 We next performed supernatant transfer assays in which either $E$. faecalis or $P$. aeruginosa single- or mixed-species biofilms were grown in iron-restricted media, and

133 their cell-free biofilm supernatants were collected and supplied to $P$. aeruginosa at a

134 1:1 ratio with fresh media for subsequent growth assays. There were minimal 135 differences in PAO1 BAA-47 growth when supplemented with biofilm supernatant 136 obtained from single-species PAO1 BAA-47 biofilm as compared to supplemented 137 with water (Figure 1E). However, when PAO1 BAA-47 was grown with supernatant 138 obtained from single-species OG1RF or mixed PAO1 BAA-47 and OG1RF biofilms, 139 we observed a significant inhibition of PAO1 BAA-46 growth as compared to control 140 supplementation (Figure 1E), suggesting that $P$. aeruginosa inhibition is mediated by 141 the presence of $E$. faecalis. 
143 Next, to validate the above findings and to determine the mechanistic basis of

144 polymicrobial interactions between $E$. faecalis and $P$. aeruginosa in iron-restricted 145 conditions, we performed mixed-species macrocolony biofilm assays $(57,58)$, initially 146 using $E$. faecalis OG1RF and $P$. aeruginosa PAO1 for our experiments. However, 147 PAO1-WT was sensitive to iron restriction at 22D concentrations greater than $1 \mathrm{mM}$ 148 (Supplementary Figure 1A) and had a minimum inhibitory concentration (MIC) of 0.8 $149 \mathrm{mM}$ to 22D (data not shown), while there was no effect on OG1RF at this concentration 150 (Figure 1F). As such, a $P$. aeruginosa PAO1 spontaneous mutant that was resistant 151 to 22D chelation was generated and named PADP6. Whole genome sequencing of 152 this mutant revealed a single nucleotide polymorphism in the nalC repressor gene 153 (4166561G>T, R15L). Although it is unclear how this mutation enhanced 22D 154 resistance in PADP6, mutation in nalC causes an overexpression of the iron-regulated 155 mexAB-oprM operon encoding the MexAB-OprM efflux pump upon severe iron 156 restriction $(59,60)$. The mutation in PADP6 restored growth in $2 \mathrm{mM} \mathrm{22D}$ to similar 157 levels as PAO1-WT macrocolonies grown in unchelated media (Supplementary

158 Figure 1A). Additionally, we observed no growth defects in either strain in unchelated 159 or at sub-inhibitory concentration of 22D (Supplementary Figure 1B). Moving forward, 160 E. faecalis OG1RF and $P$. aeruginosa PADP6 were used for all subsequent 161 experiments.

163 To validate that PADP6 was also susceptible to $E$. faecalis-mediated growth inhibition 164 when iron was restricted (supplemented with $2 \mathrm{mM} \mathrm{22D),} \mathrm{we} \mathrm{performed} \mathrm{the}$ macrocolony biofilm assay and observed that PADP6 growth was inhibited in mixedspecies macrocolonies compared to PADP6 single-species macrocolonies (Figure 1E), whereas OG1RF growth in the single- and mixed-species macrocolonies was unaffected (Figure 1F). Further, the addition of ferric chloride $\left(\mathrm{FeCl}_{3}\right)$ to 22D-chelated media restored PADP6 growth in the mixed-species macrocolonies to levels similar to

170 PADP6 single-species growth in chelated media without $\mathrm{FeCl}_{3}$ supplementation 171 (Supplementary Figure 2A and 2B), indicating that PADP6 growth inhibition in 172 mixed-species macrocolonies is specific to the presence of $E$. faecalis and iron 173 restriction. The supplementation of other trace metals to 22D-chelated media were 174 unable to rescue growth inhibition of $P$. aeruginosa (Supplementary Figure 2C and 175 2D). Hence, we hypothesized that OG1RF produces a factor, or modulates the local 
environment, such that it is unfavourable for the growth of PADP6 in iron-restricted conditions.

Planktonic growth was also examined to determine whether PADP6 growth inhibition in the presence of OG1RF was specific to biofilms. In unchelated media, we observed PADP6 growth inhibition by approximately 1 log in co-culture with $E$. faecalis OG1RF compared to PADP6 alone, while OG1RF growth in co-culture remained unaffected (Supplementary Figure 3). However, PADP6 was further inhibited by more than 2 logs in the presence of 22D. Therefore, $E$. faecalis OG1RF inhibition of $P$. aeruginosa PADP6 growth is not a biofilm-specific phenotype.

\section{E. faecalis Idh1 is responsible for $P$. aeruginosa growth inhibition in iron-} restricted conditions. An E. faecalis mariner transposon library screen was performed to identify $E$. faecalis mutants that did not inhibit PADP6 planktonic growth in iron-restricted conditions. We identified six E. faecalis mutants that did not inhibit PADP6 growth when co-cultured; however, upon validation of these six mutants in the macrocolony assay, three of which were validated for failure to inhibit PADP6 growth: Idh1, gloA3 and guaB (Supplementary Table 1). Here we focused on the transposon insertion in Idh1 (Idh1::Tn). In E. faecalis, there are two copies of Idh (Idh1 and Idh2) that encode L-lactate dehydrogenase $(\mathrm{LDH})$ to catalyse the reduction of pyruvate to L-lactate (61). Of the two copies, Idh1 accounts for the majority of L-lactate produced in E. faecalis in laboratory settings $(61,62)$.

We then created a Idh1 deletion mutant (OG1RF $\Delta / d h 1)$ and validated the transposon screening results in a macrocolony biofilm assay with PADP6 and OG1RF $\Delta / d h 1$. Specifically, PADP6 growth was not inhibited in the mixed PADP6 and OG1RF $\Delta / d h 1$ macrocolonies compared to mixed PADP6 and OG1RF macrocolonies (Figure 2A). Importantly, OG1RF $\Delta / d h 1$ growth in single- and mixed-species macrocolonies was unaffected (Figure 2B). Upon ldh1 chromosomal complementation in OG1RF $\Delta / d h 1$, PADP6 growth was inhibited to levels as when grown with OG1RF (Figure 2A), suggesting that Idh1 plays a role in inhibiting PADP6 growth in iron-restricted conditions. 
E. faecalis-derived L-lactate is responsible for $P$. aeruginosa growth inhibition in mixed-species macrocolonies when iron is restricted. In a previous study, the

211 amount of lactate exported in the supernatant of $E$. faecalis V583 $\Delta / d h 1$ was lower 212 than $E$. faecalis V583 (62). Thus, to investigate the possible role of L-lactate in 213 inhibiting PADP6 growth in mixed-species macrocolonies grown in iron-restriction 214 conditions, we quantified the extracellular L-lactate. We detected significantly more L215 lactate from OG1RF single-species macrocolonies grown in iron-restricted compared 216 to unchelated conditions (Figure $\mathbf{2 C}$ ), indicating that OG1RF increased L-lactate 217 production in iron-restricted media is independent of PADP6 presence. Increased L218 lactate production was further supported by transcriptomic data, in which we observed 219 upregulation of $I d h 1$ (log2FC $=0.57)$ in OG1RF single-species macrocolonies grown 220 in iron-restricted media compared to those grown in unchelated media (Table 1). Next, we detected a significant reduction of L-lactate in mixed PADP6 and OG1RF macrocolonies compared to OG1RF single-species macrocolonies in unchelated media, whereas comparable L-lactate levels between single- and mixed-species were detected in iron-restricted conditions (Figure 2C). Based on transcriptomic data, we observed an upregulation of Idh1 (log2FC = 3.27) in mixed PADP6 and OG1RF macrocolonies grown in iron-restricted media compared to those grown in unchelated media (Table 1). Together, these data indicate that Idh1 is upregulated when iron is restricted, leading to increase production and export of L-lactate. In previous studies, lactate was found to chelate iron $(63,64)$, which we confirmed in our assay conditions for ferric iron (Figure 2D). Consequently, even mild iron chelating effects of $E$. faecalisderived L-lactate could further restrict iron availability in the environment.

To confirm this, we compared PADP6 and OG1RF transcriptomes of mixed PADP6 and OG1RF macrocolonies to mixed PADP6 and OG1RF $\Delta / d h 1$ macrocolonies grown in iron-restricted media. Unfortunately, due to the low PADP6 cell numbers in the mixed PADP6 and OG1RF macrocolonies and therefore, lesser number of PADP6 raw counts, we were unable to draw conclusions regarding iron availability based on the gene expression profile of PADP6 (Supplementary Table 2). However, OG1RF iron acquisition genes, such as $A B C$ transporters (65), were upregulated in the mixed PADP6 and OG1RF macrocolonies, suggesting that iron availability was restricted when L-lactate levels was high (Supplementary Table 3). Consistent with this, increased L-lactate levels in the environment was inversely correlated with PADP6 
growth in the mixed PADP6 and OG1RF macrocolonies in iron-restricted conditions (Figure 2A and 2C).

246 Due to the anionic nature of L-lactate at all metabolic $\mathrm{pH}$, it cannot pass through the 247 E. faecalis cell membrane freely (61). As a result, L-lactate is exported out of $E$. 248 faecalis as lactic acid (55) with a pKa of $3.86(66-68)$ which is lower than the surrounding environmental $\mathrm{pH}$. Therefore, upon export, lactic acid is deprotonated to L-lactate and releases $\mathrm{H}^{+}$into the environment resulting in a lowered environmental $\mathrm{pH}$. To further investigate the role of L-lactate, we supplemented increasing amounts of lactic acid to mixed PADP6 and OG1RF $\Delta / d h 1$ macrocolonies in 22D-chelated media. We observed a dose-dependent inhibition of PADP6 growth in the mixedspecies macrocolonies with increasing lactic acid concentrations from $2.5 \mathrm{mM}$ to 10 $\mathrm{mM}$ (Figure 2E), while OG1RF $\Delta / d h 1$ growth in the mixed-species macrocolonies remained relatively unchanged (Figure $2 \mathrm{~F}$ ).

L-lactate is necessary, but not sufficient, for inhibiting $P$. aeruginosa growth in iron-restricted conditions. To investigate whether L-lactate alone was sufficient for inhibiting PADP6 growth in iron-restricted media, we grew PADP6 single-species macrocolonies supplemented with increasing 22D and lactic acid concentrations. When supplemented with $10 \mathrm{mM}$ or $20 \mathrm{mM}$ lactic acid in unchelated media, PADP6 growth remained relatively unchanged compared to unchelated media without lactic acid supplementation (Figure 3A). Based on the lactic acid supplementation results obtained in Figure 2E and $\mathbf{2 F}$, we expected that PADP6 growth would be inhibited when supplemented with $10 \mathrm{mM}$ lactic acid in iron-restricted conditions. However, upon supplementation of $10 \mathrm{mM}$ lactic acid, we only observed a significant inhibition of PADP6 growth when it was grown in $4 \mathrm{mM}$ 22D-chelated media, but not in $2 \mathrm{mM}$ and $3 \mathrm{mM}$ 22D-chelated media as compared to unchelated media (Figure 3A). Whereas, when supplemented with $20 \mathrm{mM}$ lactic acid, we observed significant PADP6 growth inhibition at all tested 22D concentrations, as compared to unchelated media (Figure 3A). A possible explanation for why more lactic acid was needed to inhibit single-species PADP6 growth in $2 \mathrm{mM} 22 \mathrm{D}$ could be that $E$. faecalis $/ d h 2$ is also contributing to L-lactate production in OG1RF $\Delta / d h 1$, hence a lower amount of lactic acid was sufficient to inhibit PADP6 growth in the mixed-species macrocolonies. 
276 Taken together, these data demonstrate that L-lactate is necessary, but not sufficient,

277 for PADP6 growth inhibition in iron-restricted media.

279 Decreased environmental pH under iron restriction inhibits $\boldsymbol{P}$. aeruginosa

280 growth. Next, we investigated why PADP6 viability was lost in the presence of L-

281 lactate in iron-restricted conditions. Upon export of lactic acid by $E$. faecalis, it is

282 deprotonated into L-lactate and $\mathrm{H}^{+}$. We therefore examined whether a lowered

283 environmental $\mathrm{pH}$ contributes to PADP6 growth inhibition when iron was restricted.

284 Supplementation of iron-restricted media with $20 \mathrm{mM} \mathrm{pH}$ unadjusted lactic acid $(\mathrm{pH}$

285 2.69) resulted in significant PADP6 growth inhibition as compared to the absence of

286 lactic acid supplementation (Figure 3B). In contrast, PADP6 growth was unaffected

287 when we supplemented the media with $20 \mathrm{mM} \mathrm{pH}$ adjusted lactic acid (pH 6.60) using

288 sodium hydroxide $(\mathrm{NaOH})$ when iron was otherwise restricted (Figure 3B). To

289 examine if other organic acids had the ability to inhibit $P$. aeruginosa growth, we also

290 supplemented the iron-restricted media with citric acid to lower the environmental $\mathrm{pH}$.

291 Supplementation with $\mathrm{pH}$ unadjusted citric acid $(\mathrm{pH} 2.41)$ significantly inhibited PADP6

292 growth to below the limit of detection, while no significant growth difference was

293 observed upon supplementation with $20 \mathrm{mM} \mathrm{pH}$ adjusted citric acid using $\mathrm{NaOH}(\mathrm{pH}$

294 6.61) or in the absence of citric acid supplementation (Figure 3B). Moreover,

295 alleviation of the low $\mathrm{pH}$ in iron-restricted media with PIPES, MOPS or HEPES buffer

296 partially rescued $P$. aeruginosa growth in the mixed-species macrocolonies

297 (Supplementary figure 4). Altogether, these data show that the lowered

298 environmental $\mathrm{pH}$ as a consequence of $E$. faecalis lactic acid export, coupled with L-

299 lactate-mediated chelation of iron, plays a critical role in $P$. aeruginosa growth in iron-

$\beta 00$ restricted conditions. 


\section{DISCUSSION}

303 In this study, we sought to characterize polymicrobial interactions between commonly co-isolated $E$. faecalis and $P$. aeruginosa in an infection-relevant, iron-restricted condition. We show that $E$. faecalis inhibits $P$. aeruginosa growth when iron availability is restricted in an LDH-dependent manner. Since E. faecalis LDH1 catalyses the reduction of pyruvate to L-lactate, the increased Idh1 expression translates to an increased L-lactate production in E. faecalis. The L-lactate produced is then exported as lactic acid which then gets deprotonated into L-lactate releasing $\mathrm{H}^{+}$in the surrounding environment. Together, the chelation of iron by L-lactate and lowered $\mathrm{pH}$ environment contributes to $P$. aeruginosa growth inhibition in iron-restricted conditions.

Although we showed that $E$. faecalis antagonize $P$. aeruginosa in iron-restricted conditions in vitro, they are often co-isolated in vivo $(48,50,51,53)$. During $P$. aeruginosa wound infections, genes involved in siderophore biosynthesis are upregulated, suggesting that iron availability is indeed restricted during wound infection (69). Therefore, our in vitro assay model is infection-relevant and the contrasting observation that we observed in vitro and in vivo could be due to in-host bacterial or host mechanism that negate or override the antagonism. Our findings show that, in addition to iron-restrictive effects, $P$. aeruginosa growth inhibition is largely dependent on the effects of $\mathrm{pH}$ arising from export of $E$. faecalis lactic acid into the environment. As such, co-existence of $E$. faecalis and $P$. aeruginosa in vivo may be due to host influence on $E$. faecalis L-lactate production, or that the host buffers the environmental $\mathrm{pH}$ negating $E$. faecalis L-lactate effects (70). Another possibility could be differences in in vitro and in vivo spatial organization of $E$. faecalis and $P$. aeruginosa. When $P$. aeruginosa and $E$. faecalis were grown in vitro, they exhibit distinct spatial separation in which $P$. aeruginosa forms a structured biofilm above the

328 E. faecalis biofilm (71). Whereas during polymicrobial wound infection $(P$. aeruginosa,

329 E. faecalis, S. aureus, and F. magna), $P$. aeruginosa is seen throughout the wound 330 bed as well as at the leading edge of wound (52). Host factors might also contribute 331 and affect spatial organization as this is evident in gut microbiome spatial organization

332 (72, 73). Spatial structuring that keeps the two species physically separated could 333 blunt any local $\mathrm{pH}$ and iron-competition effects. 
335 An outstanding question from this work is how iron restriction leads to an upregulation

336 of E. faecalis Idh1. E. faecalis possesses two copies of the Idh gene, Idh1 and Idh2,

337 both encoding for L-lactate dehydrogenase (61). Both isoenzymes contributes to L-

338 lactate production through catalysing the reduction of pyruvate to L-lactate (61). The

339 activity of both isoenzymes is regulated by fructose 1,6-bisphosphate, intracellular

340 phosphate and $\mathrm{pH}$ levels (74). The principal L-lactate dehydrogenase, encoded by

341 Idh1, was suggested to be post-transcriptionally regulated upon different growth rates

342 (75). The transcription of $I d h 1$ is also activated by $\operatorname{CcpA}$, a global transcription

343 regulator of carbon catabolite repression by binding to a catabolite-responsive

344 elements (cre) box identified upstream of Idh1 gene (76). However, little is known if

345 iron levels play any role in regulating Idh1 expression. We show that E. faecalis Idh1

346 expression is increased in iron-restricted media and this is supported by an increased

347 amount of L-lactate measured in the surrounding environment of macrocolonies grown.

348 Ferric uptake regulator (Fur) is a transcription factor involved in regulating iron uptake 349 and homeostasis (77). The DNA-binding sequence of Fur is well-studied $(65,78,79)$

350 and we tried using different DNA Fur binding motifs to identify possible Fur binding

351 sites upstream of $I d h 1$, but we did not find any that resemble known binding motifs.

352 Despite this, a previous study reported that $I d h 1$ is differentially expressed between $E$.

353 faecalis OG1RF and OG1RF $\Delta$ fur mutant, suggesting that Idh1 expression is directly

354 or indirectly influenced by Fur (65). An upregulation of Idh1 and several genes involved

355 in iron transport is also observed in another transcriptome study done when E. faecalis

356 was exposed to urine (80). It is therefore consistent that in iron-restricted environments,

357 such as urine or $E$. faecalis macrocolonies growing in iron-restricted media, Idh1

358 expression is induced. This observation is not limited to $E$. faecalis as Idh1 expression

359 is similarly induced in iron-restricted conditions for the anaerobe Clostridium

360 acetobutylicum (81). Although it remains unclear how iron levels influence Idh1

361 expression in $E$. faecalis, it is tempting to speculate that there is an interplay between

362 iron levels and energy metabolism during growth in iron-restricted conditions.

364 Lactic acid exported by $E$. faecalis is deprotonated to L-lactate and $\mathrm{H}^{+}$. We show that 365 the consequential lowered environmental $\mathrm{pH}$ contributes to $P$. aeruginosa growth 366 inhibition when iron is restricted. This is not surprising as $P$. aeruginosa growth is 367 generally affected at low $\mathrm{pH}$ and $P$. aeruginosa prefers to grow in a more neutral $\mathrm{pH}$ 368 range $(82,83)$. In fact, $E$. faecalis $V 583$ adopts a similar strategy of lowering 
environmental $\mathrm{pH}$ as a result of lactic acid export to inhibit Klebsiella pneumoniae growth in polymicrobial biofilms (84). Even though a $P$. aeruginosa PADP6 strain that is able to grow in iron-restricted conditions is used to study the polymicrobial interactions with $E$. faecalis, the lowered iron availability resulted from 22D-mediated iron chelation and L-lactate-mediated iron chelation is likely an added stress apart from the lowered $\mathrm{pH}$ environment. Afterall, iron is an essential element for many cellular and metabolite processes $(85,86)$. Moreover, the low $\mathrm{pH}$ might also affect the binding affinity of iron to $P$. aeruginosa siderophores. The binding affinity for iron and zinc of $E$. coli Nissle siderophore yersiniabactin changes accordingly to $\mathrm{pH}$, in which yersiniabactin preferentially binds to zinc as $\mathrm{pH}$ increases (87). Hence, the low $\mathrm{pH}$ environment created by $E$. faecalis might possibly affect $P$. aeruginosa siderophoremediated iron uptake and consequently, negatively impacting its growth due to insufficient intracellular iron.

It remains unclear how nalC mutation in PADP6 which overexpresses MexAB-OprM efflux pump confers tolerance to iron starvation (59). Although $P$. aeruginosa PvdRTOpmQ $(88,89)$ and MexAB-OprM (60) efflux pumps are implicated in pyoverdine secretion, recent research suggests that MexAB-OprM efflux pump is not involved (89). An alternative hypothesis is that PADP6 might have a compromised outer membrane. In E. coli, $\Delta$ tonB mutants were found to grow poorly in iron-restricted media and prolonged incubation resulted in mutations in yejM gene which encodes for a putative inner to outer membrane cardiolipin transporter (90). The transport of iron chelator, enterobactin, back into the cell is through outer membrane receptor protein FepA, which activity is dependent on energy transduced from proton motive force by TonBExbDB complex (91). Further characterization revealed that $\Delta$ tonB mutants with mutations in yejM are hypersensitive to vancomycin, suggesting that its outer membrane permeability is compromised to overcome the iron-restricted environment (90). These observations suggest that by having mutations in yejM, at the cost of having a more permeable membrane, could allow transport of enterobactin into the cell without FepA. Similarly, PADP6 might have a compromised outer membrane which facilitates the transport of pyoverdine and pyochelin into itself. aeruginosa polymicrobial interactions in vitro (Figure 4). During co-culture of $E$. 
403 faecalis and $P$. aeruginosa in unchelated media, L-lactate produced by $E$. faecalis is 404 exported out via a symporter with $\mathrm{H}^{+}$as lactic acid. Since the $\mathrm{pKa}$ of lactic acid is lower 405 than $\mathrm{pH}$ of the environment, it gets deprotonated into L-lactate and $\mathrm{H}^{+}$, acidifying the 406 environment. The L-lactate in the environment then chelates iron in the media (Figure

407 4A). In contrast, during co-culture in iron-restricted conditions, there is an upregulation 408 of $E$. faecalis Idh1 expression which translates to an increased L-lactate production 409 and lactic acid exported, further acidifying the environment. As E. faecalis continues 410 to grow and lactic acid accumulates over time, the L-lactate in the environment further 411 restricts iron availability in the iron-restricted media and the acidity of the environment 412 subsequently exceeds a $\mathrm{pH}$ threshold at which $P$. aeruginosa can no longer grow 413 (Figure 4B).

415 Many infections are often polymicrobial and our work highlights the importance of how 416 changes in microenvironment such as iron, $\mathrm{pH}$ levels, or host-related factors can 417 significantly influence the interactions between two bacterial species. Knowledge of 418 such in vitro antagonism between species could potentially be used as a basis for 419 additional control strategies against specific bacterial pathogens in the management 420 of infections. 
423 Bacterial strains and growth conditions. Bacterial strains used in this study are 424 listed in Supplementary Table 4. Unless stated, all $P$. aeruginosa and $E$. faecalis bacterial strains were grown at $37^{\circ} \mathrm{C}$ in shaking or static conditions for $16-18 \mathrm{~h}$, respectively. Cells were harvested by centrifugation at $12,000 \mathrm{~g}$ for $5 \mathrm{~min}$ and cell pellets were washed twice with $1 \mathrm{~mL}$ of $1 \mathrm{X}$ sterile phosphate buffered saline (PBS). The final pellet was resuspended in $3 \mathrm{~mL}$ of $1 \mathrm{X}$ sterile PBS prior to optical density (OD) measurement at $600 \mathrm{~nm}$. Cell suspensions were then normalized to the required cell number for different experimental assays. For Pseudomonas selection, bacteria were spotted onto Pseudomonas Isolation agar (PIA) (Difco ${ }^{\mathrm{TM}}$ BD, USA) supplemented with $100 \mu \mathrm{g} / \mathrm{mL}$ ampicillin (Sigma-Aldrich, USA). For E. faecalis OG1RF selection, bacteria were spotted onto Tryptone Soya Broth (TSB) (Oxoid, Canada) solidified with 1.5\% agar (Oxiod Technical No. 3) and supplemented with $10 \mathrm{mM}$ glucose (TSBG), 10 $\mu \mathrm{g} / \mathrm{mL}$ colistin (Sigma-Aldrich, USA) and $10 \mu \mathrm{g} / \mathrm{mL}$ nalidixic acid (Sigma-Aldrich, USA), respectively.

Planktonic, static biofilm and macrocolony biofilm assays. Bacterial cultures were normalized to $1-2 \times 10^{8} \mathrm{CFU} / \mathrm{mL}$ in $1 \mathrm{X}$ PBS. Macrocolonies were produced by inoculating $5 \mu \mathrm{L}$ of the respective bacterial cultures onto the surface of TSBG solidified with $1.5 \%$ agar and incubated at $37{ }^{\circ} \mathrm{C}$ for either $24 \mathrm{~h}$ or $48 \mathrm{~h}$. For mixed-species macrocolonies, bacterial species were mixed at a 1:1 ratio. When appropriate, the TSBG agar was further supplemented with or without 2,2' Bipyridyl (22D) (SigmaAldrich, USA), iron (III) chloride hexahydrate (Merck, USA), citric acid (Merck, USA), lactic acid, iron (II) sulfate heptahydrate, copper (II) chloride anhydrous, manganese (II) sulfate, magnesium

(II) chloride, zinc chloride anhydrous, 1,4-

447 Piperazinediethanesulfonic acid disodium salt (PIPES), 4-Morpholinepropanesulfonic acid, 3-(N-Morpholino)propanesulfonic acid (MOPS) or 4-(2-hydroxyethyl)-1piperazineethanesulfonic acid (HEPES) buffer (all purchased from Sigma-Aldrich, USA). Macrocolonies were excised and resuspended in $2 \mathrm{~mL}$ of sterile $1 \mathrm{X}$ PBS, followed by bacteria enumeration on respective selection agar. For supernatant transfer and static biofilm assays, single- and mixed-species inocula were prepared as described above and inoculated in TSBG media for $24 \mathrm{~h}$ at $37^{\circ} \mathrm{C}$ unless stated otherwise. For static biofilm assays, CFU enumeration were performed first by 
scraping the wells of 6-well microtiter plates, then pipetting to mix homogenously and serially diluted for plating on selective agar plates. For preparation of supernatant media, $24 \mathrm{~h}$ biofilms were first scraped, suspended in conical tubes (cells and spent media together) and centrifuged at 4,000 rpm for $20 \mathrm{~min}$ to pellet the cells. Spent media is transferred to a new tube and filter-sterilized to obtain cell-free supernatant. The cell-free supernatant was then mixed with fresh TSBG media or water, and then supplemented with $1 \mathrm{mM} 22 \mathrm{D}$, prior to inoculating for subsequent growth at $37^{\circ} \mathrm{C}$ in static conditions for $24 \mathrm{~h}$. For planktonic assay, $5 \mu \mathrm{L}$ of the respective bacterial cultures were inoculated into TSBG media and incubated at $37^{\circ} \mathrm{C}$ in shaking conditions for 24 $\mathrm{h}$.

Construction of PADP6 and PADP6-mCherry strains. Overnight cultures of PAO1WT were diluted to $10^{9}, 10^{8}, 10^{7}$ and $10^{6} \mathrm{CFU} / \mathrm{mL}$ in $1 \mathrm{XPBS}$, and $300 \mu \mathrm{L}$ of each cell suspension were plated onto LB Lennox agar (Difco ${ }^{\mathrm{TM}} \mathrm{BD}$, USA) supplemented with 1.5, 2, 2.5, 3 and $4 \mathrm{mM} 22 \mathrm{D}$. Plates were incubated at $37^{\circ} \mathrm{C}$ for 24 to $36 \mathrm{~h}$. PAO1-WT and few colonies that grew in $3 \mathrm{mM} 22 \mathrm{D}$-chelated condition were isolated and gDNA extracted using Wizard $®$ Genomic DNA Purification Kit (Promega, USA) for use in whole genome sequencing. PADP6 was chromosomally tagged with mCherry through triparental conjugation using PADP6 as a recipient with delivery plasmid pUC18miniTn7-Ptac-mCherry (E. coli) and helper plasmid pTNS1 (E. coli) resulting in PADP6mCherry (92-94).

Genome sequencing and analysis. Raw reads were imported into CLC Genomics Workbench 8.0 (Qiagen, Germany), followed by quality trimming to remove bad quality reads. The trimmed reads were then mapped to the reference genome before the Basic Variant Detection module was used to detect for mutations using the default parameters. The mutations detected in the isolate was then filtered against PAO1-WT control to determine the mutations acquired for survival in iron-restricted conditions.

Planktonic growth assay. Bacterial cultures were normalized to OD600 of 0.01 in the respective media and inoculated into 24-well microtiter plates. All microtiter plates were incubated at $37^{\circ} \mathrm{C}$ in shaking conditions. Planktonic growth was measured by recording the $\mathrm{OD}_{600}$ between 30 min to $1 \mathrm{~h}$ intervals using a Tecan Infinite $\odot$ M200 Pro 
spectrophotometer (Tecan Group Ltd., Switzerland) until early stationary growth phase was reached.

E. faecalis transposon library screen. An E. faecalis OG1RF mariner transposon library consisting of 14,978 mutants was cryogenically stocked in 96-well microtiter plates (95). These OG1RF transposon mutants were cultured in $180 \mu \mathrm{L} \mathrm{BHI} \mathrm{broth} \mathrm{at}$ $37{ }^{\circ} \mathrm{C}$ in static conditions for $16-18 \mathrm{~h}$ in 96-well microtiter plates using a cryoreplicator (Adolf Kühner AG, Switzerland) and spotted onto BHI agar plates for incubation at $37^{\circ} \mathrm{C}$ for $24 \mathrm{~h}$. Following that, OG1RF transposon mutants from the $\mathrm{BHI}$ agar plates were cultured for primary screening in $180 \mu \mathrm{L} \mathrm{BHI}$ broth as described above. PADP6-mCherry cultures were grown and washed as described above. Both the OG1RF transposon mutant cultures and PADP6-mCherry were normalized to $\mathrm{OD}_{600}$ of 0.01 in TSBG media supplemented with $1.2 \mathrm{mM} \mathrm{22D.} \mathrm{A} \mathrm{primary} \mathrm{screen} \mathrm{of}$ the $E$. faecalis transposon library was done by mixing the normalized OG1RF transposon mutant cultures and PADP6-mCherry at a 1:1 ratio in 96-well microtiter plates (total volume of $200 \mu \mathrm{L}$ ). The microtiter plates were then incubated at $37^{\circ} \mathrm{C}$ in static conditions for $22 \mathrm{~h}$. The growth of PADP6-mCherry was quantified by measuring $\mathrm{mCherry}$ fluorescence intensity (excitation $=480 \mathrm{~nm}$, emission $=615 \mathrm{~nm}$ ) using a Tecan Infinite@ M200 Pro spectrophotometer. Secondary validation of the OG1RF transposon mutants was performed by mixed-species macrocolony biofilm assays as described above to quantify the growth of PADP6 and each transposon mutant (CFU/mL) in $1 \mathrm{mM} \mathrm{22D}$ iron-restricted conditions at $37^{\circ} \mathrm{C}$ for $24 \mathrm{~h}$.

Molecular cloning. The primers used in this study are listed in Supplementary Table 5. Transformants were screened using respective selection agar as follows: (A) E. coli strains, LB with $500 \mu \mathrm{g} / \mathrm{mL}$ erythromycin (pGCP213); and (B) E. faecalis strains, BHI with $25 \mu \mathrm{g} / \mathrm{mL}$ erythromycin (pGCP213). Generation of $E$. faecalis knock-out mutants were done by allelic replacement using a temperature-sensitive shuttle vector described previously (96). Vector pGCP213 was linearized using restriction enzymes (New England Biolabs, USA) for the construction of OG1RF $\Delta / d h 1$ and OG1RF $\Delta / d h 1:: / d h 1$. Linearized vector and inserts were ligated using In-Fusion $®$ HD Cloning Kit (Clontech, Takara, Japan) and transformed into Stellar ${ }^{\mathrm{TM}}$ competent cells. Successful plasmid constructs were verified by Sanger sequencing and subsequently extracted and transformed into OG1RF. Transformants were selected with 
erythromycin at $30{ }^{\circ} \mathrm{C}$, then passaged at non-permissive temperature at $42{ }^{\circ} \mathrm{C}$ with erythromycin to select for bacteria with successful plasmid integration into the chromosome. For plasmid excision, bacteria was serially passaged at $37^{\circ} \mathrm{C}$ without erythromycin for erythromycin-sensitive colonies. These colonies were then subjected to PCR screening for detection of deletion mutant (OG1RF $\triangle O G 1 R F \_10021$ ) or chromosomal complementation of Idh1 (OG1RF $\Delta / d h 1:: / d h 1)$.

Lactate-Glo ${ }^{\mathrm{TM}}$ assay. L-lactate quantification was done using the Lactate-Glo ${ }^{\mathrm{TM}}$ assay kit (Promega, USA). Macrocolonies were excised, resuspended in $5 \mathrm{~mL}$ of sterile $1 \mathrm{X}$ PBS and homogenized. Supernatant were then collected by centrifuging homogenate at 5,000 $\mathrm{g}$ for $10 \mathrm{~min}$ and used for L-lactate quantification. Briefly, an equal volume of Lactate Detection Reagent was added to the supernatant, and incubated for $60 \mathrm{~min}$ at room temperature before luminescence was read using a Tecan Infinite@ M200 Pro spectrophotometer.

Total iron quantification. Iron quantification was done using the Iron Assay Kit (Colorimetric) (Abcam, UK) as per manufacturer's instruction. Prior to quantification, samples were prepared by supplementing different concentrations of 22D or sodium L-lactate (Sigma-Aldrich, USA) to $200 \mu \mathrm{M}$ iron (II) sulfate heptahydrate $\left(\mathrm{FeSO}_{4} \cdot 7 \mathrm{H}_{2} \mathrm{O}\right)$ and iron (III) chloride hexahydrate $\left(\mathrm{FeCl}_{3} \cdot 6 \mathrm{H}_{2} \mathrm{O}\right)$. The output was measured immediately at OD593 using a Tecan Infinite $@$ M200 Pro spectrophotometer. The iron concentration in each sample was computed based on the standard curve generated using the iron standards.

RNA extraction from macrocolonies. Matured single and mixed-species macrocolonies grown for $48 \mathrm{~h}$ on TSBG agar supplemented with and without 2,2' bipyridyl, in biological triplicates, were first scraped into RNAprotect ${ }^{\mathrm{TM}}$ Bacteria Reagent (Qiagen, Germany) and incubated at room temperature for 5 mins before centrifuging at $10,000 \mathrm{~g}$ for 10 mins. The supernatant was decanted and bacteria pellets collected were then subjected to total RNA extraction using RNeasy® mini kit (Qiagen, Germany) with slight modifications. Briefly, cell pellets were resuspended in

553 TE buffer containing $20 \mathrm{mg} / \mathrm{mL}$ lysozyme (Sigma-Aldrich, USA) and each sample was 554 further supplemented with $20 \mu \mathrm{L}$ proteinase K (Qiagen, Germany). This was followed 
by incubation at $37^{\circ} \mathrm{C}$ for $1 \mathrm{~h}$, and subsequent extraction steps was performed according to manufacturer's protocol. Extracted RNA samples were treated with DNase (TURBO DNA-free ${ }^{\mathrm{TM}} \mathrm{kit}$, Invitrogen, USA) for removal of contaminating genomic DNA before it was purified with Monarch® RNA cleanup kit (New England Biolabs, USA). The concentration of RNA and potential DNA contamination were quantified using Qubit ${ }^{T M}$ RNA BR and Qubit ${ }^{T M}$ dsDNA HS assay kits, respectively (Invitrogen, USA). The extracted RNA was quality checked using a TapeStation instrument (RNA ScreenTape, Aligent Technologies, USA) before it was sent for sequencing. Every sample had to have a minimum RNA concentration of $40-80$ $\mathrm{ng} / \mu \mathrm{L}$, a maximum of $10 \%$ DNA contamination and a RINe value $\geq 8.0$, before being used for library preparation and subsequent sequencing as $100 \mathrm{bp}$ paired end reads on an Illumina HiSeq2500 at Singapore Centre for Environmental Life Sciences Engineering (SCELSE) sequencing facility.

Transcriptomic analysis. The raw reads obtained were checked using FastQC (Version 0.11.9) and adaptor trimmed using bbduk from BBMap tools (Version 39.79) (97). Trimmed reads were then mapped using bwa-mem of BWA (Version 0.7.17r1188) with options “-T 20 -k 13" against E. faecalis OG1RF (NCBI accession: CP002621) or $P$. aeruginosa PAO1 (NCBI accession: NC_002516) reference genomes. Reads mapped to predicted open reading frames were quantified using htseq-count of HTSeq (Version 0.12.4) with option "-m intersection-strict" (98). Ribosomal sequences were filtered out from all data sets. Differential gene expression analysis was performed in $\mathrm{R}$ using edgeR (Version 3.28.1) (99). The log2 fold change values extracted were based on the false discovery rate $(\mathrm{FDR})<0.05$.

Statistical analysis. Statistical analyses were performed with GraphPad Prism software (Version 9.0.0, California, USA) and are described in the respective figure 582 legends.

Data availability. All RNA-seq sequences were deposited in the National Center for number GSE190090. 


\section{ACKNOWLEDGEMENTS}

589 This work was supported by the National Research Foundation and Ministry of

590 Education Singapore under its Research Centre of Excellence Programme, by the

591 Singapore Ministry of Education under its Tier 2 program (MOE2014-T2-1-129)

592 awarded to K.A.K., and by NIAID R21 AI37446 to J.A.L. Preparation of this article was

593 also financially supported by the Interdisciplinary Graduate Programme of Nanyang

594 Technological University. We thank Yang Liang from Southern University of Science

595 and Technology for the P. aeruginosa PAO1-WT and E. coli strains, Sam P. Brown

596 from Georgia Institute of Technology for the $P$. aeruginosa clinical isolates and Michael

597 S. Gilmore from Harvard Medical school for the E. faecalis clinical isolates.

598

599 Figure 4 in this article was created with BioRender.com.

600

\section{CONFLICT OF INTEREST}

602

603 The authors declare that they have no conflicts of interest with the contents of this 604 article. 
605

606

607

608

609

610

611

612

613

614

615

616

617

618

619

620

621

622

623

624

625

626

627

628

629

630

631

632

633

634

635

636

\section{REFERENCES}

1. Brogden KA, Guthmiller JM, Taylor CE. 2005. Human polymicrobial infections. The Lancet 365:253-255.

2. Nelson A, De Soyza A, Perry JD, Sutcliffe IC, Cummings SP. 2012. Polymicrobial challenges to Koch's postulates: ecological lessons from the bacterial vaginosis and cystic fibrosis microbiomes. Innate Immunity 18:774783.

3. Bakaletz LO. 2004. Developing animal models for polymicrobial diseases. Nature Reviews Microbiology 2:552-568.

4. Bowler P, Duerden B, Armstrong DG. 2001. Wound microbiology and associated approaches to wound management. Clinical Microbiology Reviews 14:244-269.

5. Frank DN, Wysocki A, Specht-Glick DD, Rooney A, Feldman RA, St. Amand AL, Pace NR, Trent JD. 2009. Microbial diversity in chronic open wounds. Wound Repair and Regeneration 17:163-172.

6. Pastar I, Nusbaum AG, Gil J, Patel SB, Chen J, Valdes J, Stojadinovic O, Plano LR, Tomic-Canic M, Davis SC. 2013. Interactions of methicillin resistant Staphylococcus aureus USA300 and Pseudomonas aeruginosa in polymicrobial wound infection. Plos One 8.

7. Mertz PM. 2003. Cutaneous biofilms: friend or foe? Wounds 15:129-132.

8. Darveau RP. 2010. Periodontitis: a polymicrobial disruption of host homeostasis. Nature Reviews Microbiology 8:481-490.

9. Roberts FA, Darveau RP. 2015. Microbial protection and virulence in periodontal tissue as a function of polymicrobial communities: symbiosis and dysbiosis. Periodontology 2000 69:18-27.

10. Bakaletz LO. 2010. Immunopathogenesis of polymicrobial otitis media. Journal of Leukocyte Biology 87:213-222.

11. Marom T, Nokso-Koivisto J, Chonmaitree T. 2012. Viral-bacterial interactions in acute otitis media. Current Allergy and Asthma Reports 12:551-558.

12. Mobley H, Warren JW. 1987. Urease-positive bacteriuria and obstruction of long-term urinary catheters. Journal of Clinical Microbiology 25:2216-2217. 
13. Siegman-Igra Y, Kulka T, Schwartz D, Konforti N. 1994. Polymicrobial and monomicrobial bacteraemic urinary tract infection. Journal of Hospital Infection 28:49-56.

14. Warren JW, Tenney JH, Hoopes JM, Muncie HL, Anthony WC. 1982. A prospective microbiologic study of bacteriuria in patients with chronic indwelling urethral catheters. The Journal of Infectious Diseases 146:719-723.

15. Croxall G, Weston V, Joseph S, Manning G, Cheetham P, McNally A. 2011. Increased human pathogenic potential of Escherichia coli from polymicrobial urinary tract infections in comparison to isolates from monomicrobial culture samples. Journal of Medical Microbiology 60:102-109.

16. Lyczak JB, Cannon CL, Pier GB. 2002. Lung infections associated with cystic fibrosis. Clinical Microbiology Reviews 15:194-222.

18. Filkins L, Hampton T, Gifford A, Gross M, Hogan D, Sogin M, Morrison H,

17. Coburn B, Wang PW, Caballero JD, Clark ST, Brahma V, Donaldson S, Zhang Paster B, O'Toole G. 2012. Prevalence of Streptococci and increased polymicrobial diversity associated with cystic fibrosis patient stability. Journal of

20. Sibley CD, Parkins MD, Rabin HR, Duan K, Norgaard JC, Surette MG. 2008. A Bacteriology 194:4709-4717.

19. Shinzato T, Saito A. 1995. The Streptococcus milleri group as a cause of pulmonary infections. Clinical Infectious Diseases 21:S238-S243. polymicrobial perspective of pulmonary infections exposes an enigmatic pathogen in cystic fibrosis patients. Proceedings of the National Academy of Sciences 105:15070-15075.

21. Black CE, Costerton JW. 2010. Current concepts regarding the effect of wound microbial ecology and biofilms on wound healing. Surgical Clinics 90:11471160.

22. Ebright JR. 2005. Microbiology of chronic leg and pressure ulcers: clinical significance and implications for treatment. Nursing Clinics 40:207-216.

23. Serralta VW, Harrison-Balestra C, Cazzaniga AL, Davis SC, Mertz PM. 2001. Lifestyles of bacteria in wounds: presence of biofilms? Wounds 13:29-34. 
24. Colombo APV, Magalhães CB, Hartenbach FARR, do Souto RM, da SilvaBoghossian CM. 2016. Periodontal-disease-associated biofilm: A reservoir for pathogens of medical importance. Microbial Pathogenesis 94:27-34.

25. Colombo A, Tanner A. 2019. The role of bacterial biofilms in dental caries and periodontal and peri-implant diseases: a historical perspective. Journal of Dental Research 98:373-385.

27. Lasserre JF, Brecx MC, Toma S. 2018. Oral microbes, biofilms and their role

28. Naginyte M, Do T, Meade J, Devine DA, Marsh PD. 2019. Enrichment of periodontal pathogens from the biofilms of healthy adults. Scientific Reports

29. Bakaletz LO. 2007. Bacterial biofilms in otitis media: evidence and relevance. The Pediatric Infectious Disease Journal 26:S17-S19.

30. Thornton RB, Rigby PJ, Wiertsema SP, Filion P, Langlands J, Coates HL,

31. Bakar MBA, McKimm J, Haque M. 2018. Otitis media and biofilm: An overview.

32. Hatt J, Rather P. 2008. Role of bacterial biofilms in urinary tract infections. Bacterial Biofilms:163-192.

33. Delcaru C, Alexandru I, Podgoreanu P, Grosu M, Stavropoulos E, Chifiriuc MC, Vijayasekaran S, Keil AD, Richmond PC. 2011. Multi-species bacterial biofilm and intracellular infection in otitis media. BMC Pediatrics 11:1-10. Lazar V. 2016. Microbial biofilms in urinary tract infections and prostatitis: etiology, pathogenicity, and combating strategies. Pathogens 5:65.

34. Soto SM. 2014. Importance of biofilms in urinary tract infections: new therapeutic approaches. Advances in Biology 2014.

35. Høiby N, Ciofu O, Bjarnsholt T. 2010. Pseudomonas aeruginosa biofilms in cystic fibrosis. Future Microbiology 5:1663-1674.

36. Kovach K, Davis-Fields M, Irie Y, Jain K, Doorwar S, Vuong K, Dhamani N, Mohanty K, Touhami A, Gordon VD. 2017. Evolutionary adaptations of biofilms 
infecting cystic fibrosis lungs promote mechanical toughness by adjusting polysaccharide production. npj Biofilms and Microbiomes 3:1-9.

37. Høiby N. 2002. Understanding bacterial biofilms in patients with cystic fibrosis: current and innovative approaches to potential therapies. Journal of Cystic Fibrosis 1:249-254.

38. Hall-Stoodley L, Stoodley P. 2009. Evolving concepts in biofilm infections.

39. Radlinski L, Rowe SE, Kartchner LB, Maile R, Cairns BA, Vitko NP, Gode CJ,

40. Cassat JE, Skaar EP. 2013. Iron in infection and immunity. Cell Host \& Microbe

41. Raymond KN, Dertz EA, Kim SS. 2003. Enterobactin: an archetype for microbial iron transport. Proceedings of the National Academy of Sciences 100:3584-3588.

42. Peyssonnaux C, Zinkernagel AS, Datta V, Lauth X, Johnson RS, Nizet V. 2006.

43. Baker HM, Baker EN. 2012. A structural perspective on lactoferrin function. TLR4-dependent hepcidin expression by myeloid cells in response to bacterial

44. Masson P, Heremans J, Schonne E. 1969. Lactoferrin, an iron-binbing protein Ni neutrophilic leukocytes. The Journal of Experimental Medicine 130:643-658.

45. Arias CA, Murray BE. 2012. The rise of the Enterococcus: beyond vancomycin resistance. Nature Reviews Microbiology 10:266-278.

46. Higuita NIA, Huycke MM. 2014. Enterococcal disease, epidemiology, and implications for treatment, Enterococci: From commensals to leading causes of drug resistant infection [Internet]. Massachusetts Eye and Ear Infirmary.

47. Kristich CJ, Rice LB, Arias CA. 2014. Enterococcal infection-treatment and antibiotic resistance, Enterococci: From commensals to leading causes of drug resistant infection [Internet]. Massachusetts Eye and Ear Infirmary.

48. Gjødsbøl K, Christensen JJ, Karlsmark T, Jørgensen B, Klein BM, Krogfelt KA. 2006. Multiple bacterial species reside in chronic wounds: a longitudinal study. International Wound Journal 3:225-231. 
49. Peng D, Li X, Liu P, Luo M, Chen S, Su K, Zhang Z, He Q, Qiu J, Li Y. 2018. Epidemiology of pathogens and antimicrobial resistanceof catheter-associated urinary tract infections in intensive care units: a systematic review and metaanalysis. American Journal of Infection Control 46:e81-e90.

50. Citron DM, Goldstein EJ, Merriam CV, Lipsky BA, Abramson MA. 2007. Bacteriology of moderate-to-severe diabetic foot infections and in vitro activity of antimicrobial agents. Journal of Clinical Microbiology 45:2819-2828.

51. Giacometti A, Cirioni O, Schimizzi A, Del Prete M, Barchiesi F, D'errico M, Petrelli E, Scalise G. 2000. Epidemiology and microbiology of surgical wound infections. Journal of Clinical Microbiology 38:918-922.

52. Dalton T, Dowd SE, Wolcott RD, Sun Y, Watters C, Griswold JA, Rumbaugh KP. 2011. An in vivo polymicrobial biofilm wound infection model to study interspecies interactions. PloS One 6.

53. Tsuchimori N, Hayashi R, Shino A, Yamazaki T, Okonogi K. 1994. Enterococcus faecalis aggravates pyelonephritis caused by Pseudomonas aeruginosa in experimental ascending mixed urinary tract infection in mice. Infection and Immunity 62:4534-4541.

54. Yamasaki H, Arakawa S, Kamidono S. 1991. Basic studies on the pathogenicity of Enterococcus faecalis: polymicrobial infection with Enterococcus faecalis and Proteus mirabilis in experimental ascending pyelonephritis models. Journal of Infection and Chemotherapy 39:651-662.

55. Harold FM, Levin E. 1974. Lactic acid translocation: terminal step in glycolysis by Streptococcus faecalis. Journal of Bacteriology 117:1141-1148.

56. Kaes C, Katz A, Hosseini MW. 2000. Bipyridine: the most widely used ligand. A review of molecules comprising at least two 2,2'-bipyridine units. Chemical Reviews 100:3553-3590.

57. Keogh D, Tay W, Ho Y, Dale J, Chen S, Umashankar S, Williams RH, Chen S, Dunny G, Kline K. 2016. Enterococcal metabolite cues facilitate interspecies niche modulation and polymicrobial infection. Cell Host \& Microbe 20:493-503.

58. Lam LN, Wong JJ, Chong KKL, Kline KA. 2020. Enterococcus faecalis manganese exporter MntE alleviates manganese toxicity and is required for mouse gastrointestinal colonization. Infection and Immunity 88.

59. Cao L, Srikumar R, Poole K. 2004. MexAB-OprM hyperexpression in NalC-type multidrug-resistant Pseudomonas aeruginosa: identification and 
characterization of the nalC gene encoding a repressor of PA3720-PA3719. Molecular Microbiology 53:1423-1436.

60. Poole K, Heinrichs DE, Neshat S. 1993. Cloning and sequence analysis of an EnvCD homologue in Pseudomonas aeruginosa: regulation by iron and possible involvement in the secretion of the siderophore pyoverdine. Molecular Microbiology 10:529-544.

61. Ramsey M, Hartke A, Huycke M. 2014. The physiology and metabolism of Enterococci, Enterococci: From Commensals to Leading Causes of Drug Resistant Infection [Internet]. Massachusetts Eye and Ear Infirmary.

62. Jönsson M, Saleihan Z, Nes IF, Holo H. 2009. Construction and characterization of three lactate dehydrogenase-negative Enterococcus faecalis V583 mutants. Applied and Environmental Microbiology 75:4901-4903.

63. Gorman J, Clydesdale F. 1984. Thermodynamic and kinetic stability constants of selected carboxylic acids and iron. Journal of Food Science 49:500-503.

64. Bergqvist SW, Sandberg A-S, Andlid T, Wessling-Resnick M. 2005. Lactic acid decreases Fe (II) and Fe (III) retention but increases Fe (III) transepithelial transfer by Caco-2 cells. Journal of Agricultural and Food Chemistry 53:69196923.

65. Latorre M, Quenti D, Travisany D, Singh KV, Murray BE, Maass A, Cambiazo V. 2018. The role of Fur in the transcriptional and iron homeostatic response of Enterococcus faecalis. Frontiers in Microbiology 9:1580.

66. Eyal AM, Canari R. 1995. pH dependence of carboxylic and mineral acid extraction by amine-based extractants: effects of pKa, amine basicity, and diluent properties. Industrial \& Engineering Chemistry Research 34:1789-1798.

67. Featherstone J, Rodgers B. 1981. Effect of acetic, lactic and other organic acids on the formation of artificial carious lesions. Caries Research 15:377-385.

68. Gonzalez MI, Alvarez S, Riera FA, Álvarez R. 2008. Lactic acid recovery from whey ultrafiltrate fermentation broths and artificial solutions by nanofiltration. Desalination 228:84-96.

69. Turner KH, Everett J, Trivedi U, Rumbaugh KP, Whiteley M. 2014. Requirements for Pseudomonas aeruginosa acute burn and chronic surgical wound infection. PLoS Genetics 10. 
70. Schneider LA, Korber A, Grabbe S, Dissemond J. 2007. Influence of pH on wound-healing: a new perspective for wound-therapy? Archives of Dermatological Research 298:413-420.

71. Lee K, Lee K-M, Kim D, Yoon SS. 2017. Molecular determinants of the thickened matrix in a dual-species Pseudomonas aeruginosa and

73. Chang C-S, Kao C-Y. 2019. Current understanding of the gut microbiota Enterococcus faecalis biofilm. Applied and Environmental Microbiology 83. shaping mechanisms. Journal of Biomedical Science 26:1-11.

75. Mehmeti I, Faergestad EM, Bekker M, Snipen L, Nes IF, Holo H. 2012. Growth rate-dependent control in Enterococcus faecalis: effects on the transcriptome and proteome, and strong regulation of lactate dehydrogenase. Applied and Environmental Microbiology 78:170-176.

76. Leboeuf C, Leblanc L, Auffray Y, Hartke A. 2000. Characterization of the ccpA gene of Enterococcus faecalis: identification of starvation-inducible proteins regulated by CcpA. Journal of Bacteriology 182:5799-5806.

77. Hassan HM, Troxell B. 2013. Transcriptional regulation by Ferric Uptake Regulator (Fur) in pathogenic bacteria. Frontiers in Cellular and Infection Microbiology 3:59.

79. Quatrini R, Lefimil C, Veloso FA, Pedroso I, Holmes DS, Jedlicki E. 2007.

78. Yu C, Genco CA. 2012. Fur-mediated global regulatory circuits in pathogenic Bioinformatic prediction and experimental verification of Fur-regulated genes in the extreme acidophile Acidithiobacillus ferrooxidans. Nucleic Acids Research 35:2153-2166. Neisseria species. Journal of Bacteriology 194:6372-6381. analysis of pathogenic and probiotic Enterococcus faecalis isolates, and their transcriptional responses to growth in human urine. PloS One 5:e12489. 
81. Vasileva D, Janssen H, Hönicke D, Ehrenreich A, Bahl H. 2012. Effect of iron limitation and fur gene inactivation on the transcriptional profile of the strict anaerobe Clostridium acetobutylicum. Microbiology 158:1918-1929.

82. Bushell FM, Tonner PD, Jabbari S, Schmid AK, Lund PA. 2019. Synergistic impacts of organic acids and $\mathrm{pH}$ on growth of Pseudomonas aeruginosa: A comparison of parametric and Bayesian non-parametric methods to model growth. Frontiers in Microbiology 9:3196.

83. Tanner RS, James SA. 1992. Rapid bactericidal effect of low pH against Pseudomonas aeruginosa. Journal of Industrial Microbiology 10:229-232.

84. Ballén V, Ratia C, Cepas V, Soto SM. 2020. Enterococcus faecalis inhibits Klebsiella pneumoniae growth in polymicrobial biofilms in a glucose-enriched medium. Biofouling 36:846-861.

85. Frawley ER, Fang FC. 2014. The ins and outs of bacterial iron metabolism. Molecular Microbiology 93:609-616.

86. Andreini C, Bertini I, Cavallaro G, Holliday GL, Thornton JM. 2008. Metal ions in biological catalysis: from enzyme databases to general principles. Journal of Biological Inorganic Chemistry 13:1205-1218.

87. Behnsen J, Zhi H, Aron AT, Subramanian V, Santus W, Lee MH, Gerner RR, Petras D, Liu JZ, Green KD. 2021. Siderophore-mediated zinc acquisition enhances enterobacterial colonization of the inflamed gut. Nature Communications 12:1-15.

88. Hannauer M, Yeterian E, Martin LW, Lamont IL, Schalk IJ. 2010. An efflux pump is involved in secretion of newly synthesized siderophore by Pseudomonas aeruginosa. FEBS Letters 584:4751-4755.

89. Imperi F, Tiburzi F, Visca P. 2009. Molecular basis of pyoverdine siderophore recycling in Pseudomonas aeruginosa. Proceedings of the National Academy of Sciences 106:20440-20445.

90. Qiu N, Misra R. 2019. Overcoming iron deficiency of an Escherichia coli tonB mutant by increasing outer membrane permeability. Journal of Bacteriology 201:e00340-19.

91. Noinaj N, Guillier M, Barnard TJ, Buchanan SK. 2010. TonB-dependent transporters: regulation, structure, and function. Annual Review of Microbiology 64:43-60. 
92. Sambrook J, Fritsch EF, Maniatis T. 1989. Molecular cloning: a laboratory manual. Cold Spring Harbor Laboratory Press.

93. Choi K-H, Gaynor JB, White KG, Lopez C, Bosio CM, Karkhoff-Schweizer RR, Schweizer HP. 2005. A Tn7-based broad-range bacterial cloning and expression system. Nature Methods 2:443-448.

94. Choi K-H, Schweizer HP. 2006. mini-Tn7 insertion in bacteria with single attTn7 sites: example Pseudomonas aeruginosa. Nature Protocols 1:153-161.

95. Kristich CJ, Nguyen VT, Le T, Barnes AM, Grindle S, Dunny GM. 2008. Development and use of an efficient system for random mariner transposon mutagenesis to identify novel genetic determinants of biofilm formation in the core Enterococcus faecalis genome. Applied and Environmental Microbiology 74:3377-3386.

96. Nielsen HV, Guiton PS, Kline KA, Port GC, Pinkner JS, Neiers F, Normark S, Henriques-Normark B, Caparon MG, Hultgren SJ. 2012. The metal iondependent adhesion site motif of the Enterococcus faecalis EbpA pilin mediates pilus function in catheter-associated urinary tract infection. MBio 3:e00177-12.

97. Bushnell B. 2015. BBMap short-read aligner, and other bioinformatics tools. University of California, Berkeley, CA.

98. Anders S, Pyl PT, Huber W. 2015. HTSeq-a Python framework to work with high-throughput sequencing data. Bioinformatics 31:166-169.

99. Robinson MD, McCarthy DJ, Smyth GK. 2010. edgeR: a Bioconductor package for differential expression analysis of digital gene expression data. Bioinformatics 26:139-140.

100. Hentzer M, Riedel K, Rasmussen TB, Heydorn A, Andersen JB, Parsek MR, Rice SA, Eberl L, Molin S, Høiby N. 2002. Inhibition of quorum sensing in Pseudomonas aeruginosa biofilm bacteria by a halogenated furanone compound. Microbiology 148:87-102.

101. Pirnay J-P, Bilocq F, Pot B, Cornelis P, Zizi M, Van Eldere J, Deschaght P, Vaneechoutte M, Jennes S, Pitt T. 2009. Pseudomonas aeruginosa population structure revisited. PLoS One 4:e7740.

102. Dunny GM, Brown BL, Clewell DB. 1978. Induced cell aggregation and mating in Streptococcus faecalis: evidence for a bacterial sex pheromone. Proceedings of the National Academy of Sciences 75:3479-3483. 
103. McBride SM, Fischetti VA, LeBlanc DJ, Moellering Jr RC, Gilmore MS. 2007. Genetic diversity among Enterococcus faecalis. PloS One 2:e582.

903 104. Guardabassi L, Larsen J, Skov R, Schønheyder HC. 2010. Gentamicinresistant Enterococcus faecalis sequence type 6 with reduced penicillin susceptibility: diagnostic and therapeutic implications. Journal of clinical Microbiology 48:3820-3821.

907

105. Lagendijk EL, Validov S, Lamers GE, De Weert S, Bloemberg GV. 2010.

908 Genetic tools for tagging Gram-negative bacteria with mCherry for visualization

909 in vitro and in natural habitats, biofilm and pathogenicity studies. FEMS Microbiology Letters 305:81-90. 
A

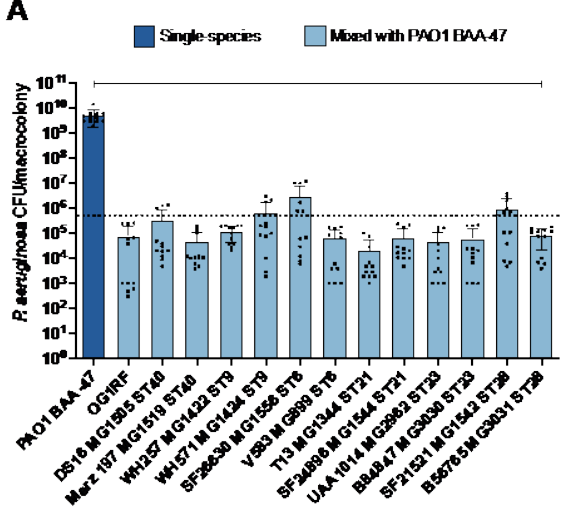

C

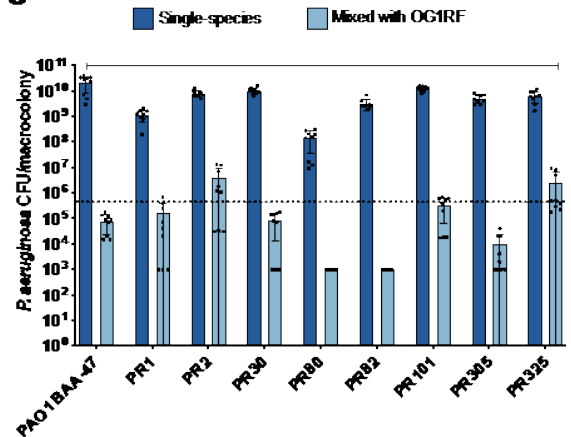

E

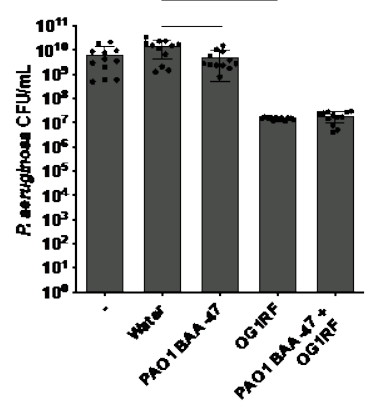

B
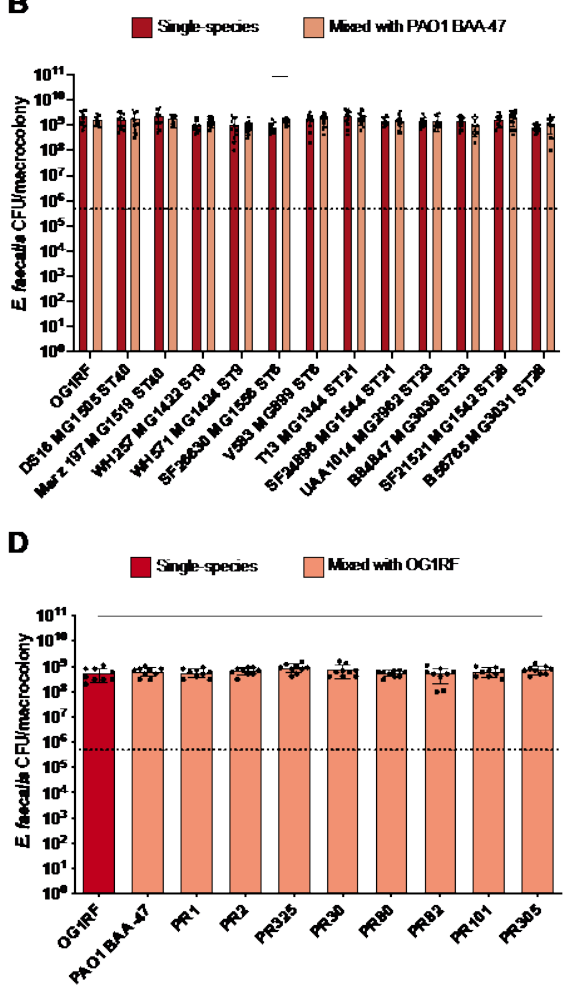

$\mathbf{G}$
$\mathbf{F}$

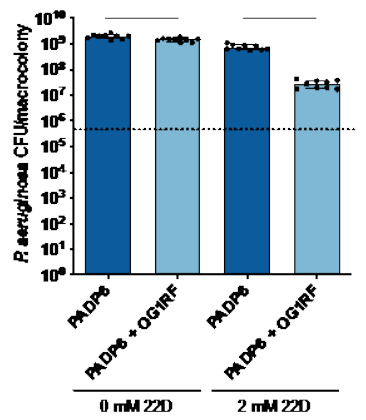

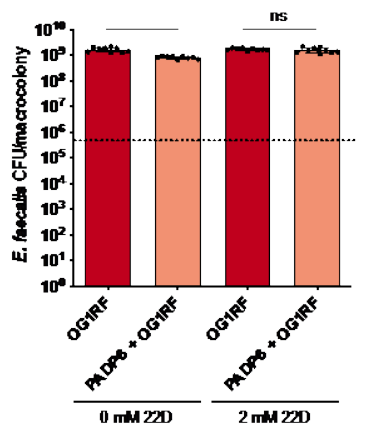

912 Figure 1 E. faecalis inhibits $P$. aeruginosa growth in iron-restricted conditions.

913 Enumeration of (A) PAO1 BAA-47, (B) E. faecalis clinical isolates, (C) $P$. aeruginosa

914 clinical isolates and (D) OG1RF from $24 \mathrm{~h}$ biofilms with single or mixed inoculums

915 grown in media supplemented with $1 \mathrm{mM}$ 22D. Dotted lines represent inoculum of

916 bacteria spotted. $\mathrm{N} \geq 3$ with 3 technical replicates; error bars represent SD from the

917 mean. Statistical analysis was performed using Mann-Whitney $U$ test, ${ }^{*} p<0.05,{ }^{* *} p<$

$9180.01,{ }^{* * *} p<0.001,{ }^{* * *} p<0.0001$. Capped line showing statistical significance in (A)

919 and (C) represents ${ }^{* * *} p<0.0001$ was observed for all comparisons made.

920 Enumeration of (E) PAO1 BAA-47 from $24 \mathrm{~h}$ cultures grown with fresh TSBG media,

921 water, or cell-free supernatant obtained from $24 \mathrm{~h}$ biofilms of PAO1 BAA-47, OG1RF

922 and PAO1 BAA-47 mixed with OG1RF. The water and respective supernatants were

923 mixed at a 1:1 ratio with fresh TSBG media supplemented with $1 \mathrm{mM} 22 \mathrm{D}$ for PAO1 
924 BAA-47 growth. $\mathrm{N}=4$ with 3 technical replicates; error bars represent SD from the 925 mean. Statistical analysis was performed using Mann-Whitney $U$ test, ${ }^{*} p<0.05$, ${ }^{* *} p<$ $9260.01,{ }^{* * *} p<0.001,{ }^{* * *} p<0.0001$. Enumeration of (F) PADP6 and (G) OG1RF from

$92724 \mathrm{~h}$ macrocolonies with single or mixed inoculums grown in media supplemented 928 without and with $2 \mathrm{mM} 22 \mathrm{D}$. Bacterial species were mixed at a 1:1 ratio for mixed929 species macrocolonies. Dotted lines represent inoculum of bacteria spotted. $\mathrm{N}=3$ with 9303 technical replicates; error bars represent SD from the mean. Statistical analysis was 931 performed using Mann-Whitney U test, ${ }^{*} p<0.05$, ${ }^{* *} p<0.01$, ${ }^{* * *} p<0.001$, ${ }^{* * *} p<$ 9320.0001. 
A

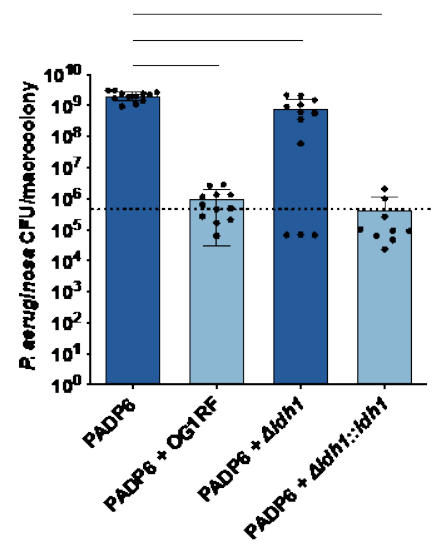

C

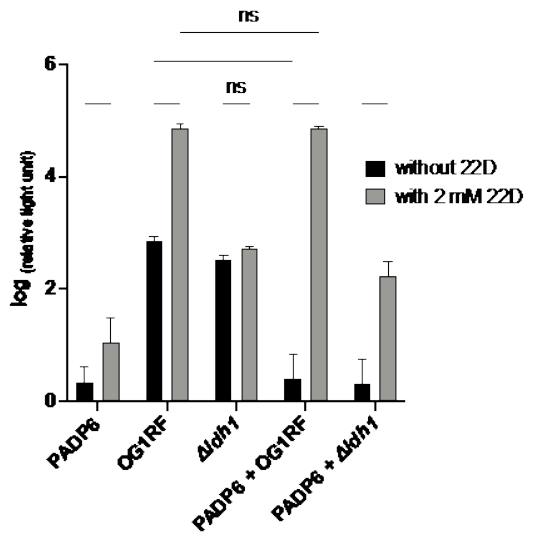

$\mathbf{E}$

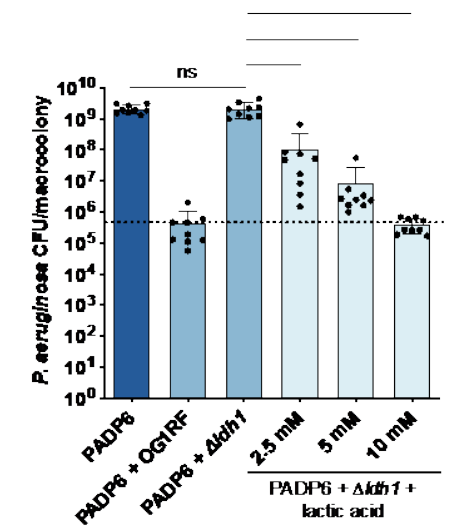

B
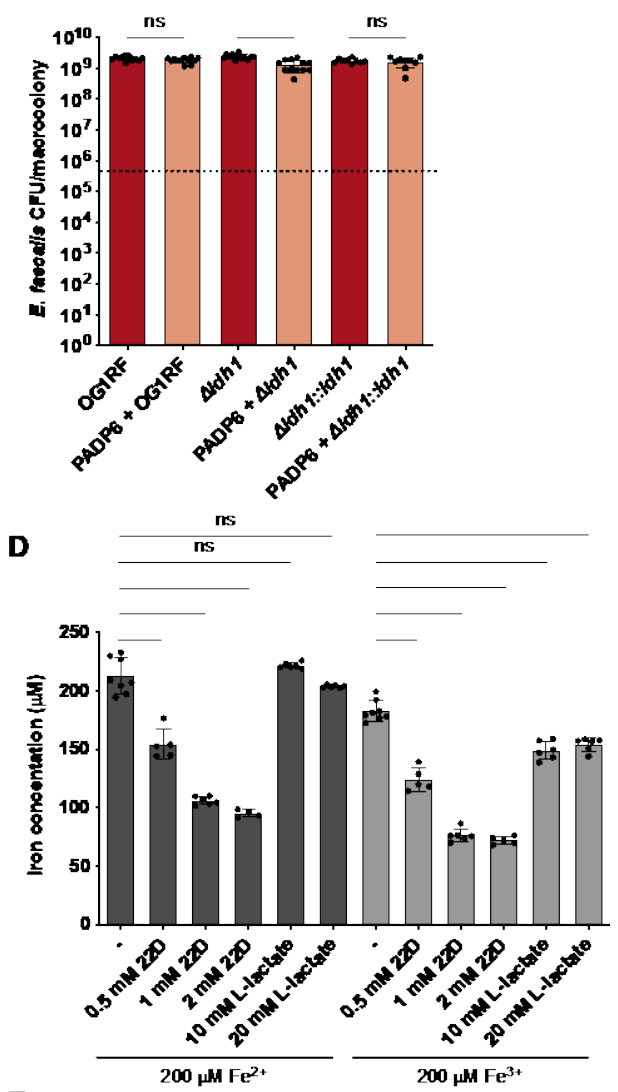

$\mathbf{F}$

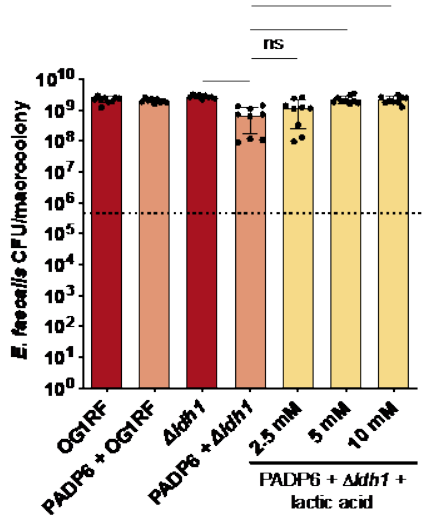

Figure 2 L-lactate produced by $E$. faecalis inhibits $P$. aeruginosa growth in ironrestricted media. Enumeration of (A) PADP6 and (B) OG1RF, $\Delta / d h 1, \Delta / d h 1:: / d h 1$ from $48 \mathrm{~h}$ macrocolonies with single or mixed inoculums grown in $2 \mathrm{mM}$ 22D-chelated media. Bacterial species were mixed at a 1:1 ratio for mixed-species macrocolonies. Dotted lines represent inoculum of bacteria spotted. $\mathrm{N} \geq 3$ with 3 technical replicates; error bars represent SD from the mean. Statistical analysis was performed using Mann-Whitney U test, ${ }^{*} p<0.05,{ }^{* *} p<0.01,{ }^{* * *} p<0.001,{ }^{* * *} p<0.0001$. (C) Quantification of L-lactate exported from $48 \mathrm{~h}$ single- and mixed-species macrocolonies grown in media supplemented without and with $2 \mathrm{mM} 22 \mathrm{D} . \mathrm{N}=3$ with 
9432 technical replicates; error bars represent SD from the mean. Statistical analysis was

944 performed using two-way ANOVA with Tukey's test for multiple comparisons, ${ }^{*} p<0.05$,

$945{ }^{* *} p<0.01,{ }^{* * *} p<0.001,{ }^{* * * *} p<0.0001$. (D) Quantification of iron when $200 \mu \mathrm{M}$ of iron

946 (II) sulfate heptahydrate $\left(\mathrm{Fe}^{2+}\right)$ and iron (III) chloride hexahydrate $\left(\mathrm{Fe}^{3+}\right)$ were

947 supplemented without and with varying concentrations of $22 \mathrm{D}(0.5,1$ and $2 \mathrm{mM})$ or L-

948 lactate (10 and $20 \mathrm{mM}$ ). $\mathrm{N} \geq 3$ with 2 technical replicates; error bars represent SD from

949 the mean. Statistical analysis was performed using Mann-Whitney $U$ test, ${ }^{*} p<0.05$,

$950{ }^{* *} p<0.01,{ }^{* *} p<0.001,{ }^{* * *} p<0.0001$. Enumeration of (E) PADP6 and (F) OG1RF,

$951 \Delta / d h 1$ from $48 \mathrm{~h}$ macrocolonies with single or mixed inoculums grown in $2 \mathrm{mM}$ 22D-

952 chelated media without and with increasing lactic acid concentrations (2.5, 5, and 10

$953 \mathrm{mM}$ ). Bacterial species were mixed at a 1:1 ratio for mixed-species macrocolonies.

954 Dotted lines represent inoculum of bacteria spotted. $\mathrm{N}=3$ with 3 technical replicates;

955 error bars represent SD from the mean. Statistical analysis was performed using Mann-Whitney U test, ${ }^{*} p<0.05,{ }^{* *} p<0.01,{ }^{* * *} p<0.001,{ }^{* * * *} p<0.0001$. 
A

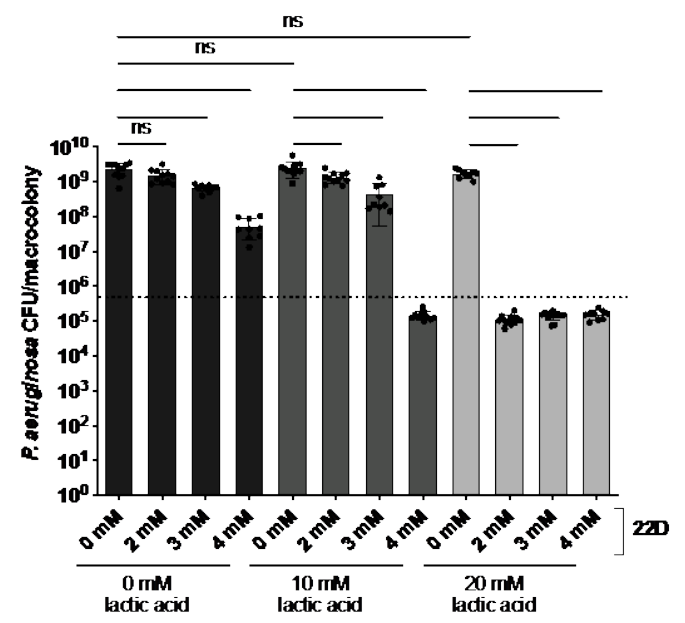

B

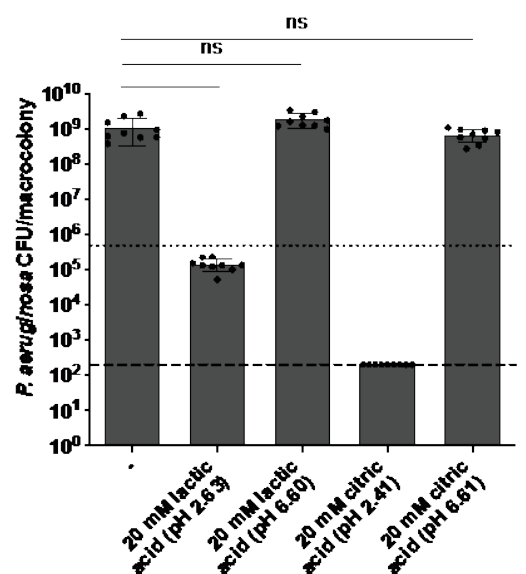

958 Figure $3 \boldsymbol{P}$. aeruginosa growth inhibition is due to lowered environmental $\mathrm{pH}$ in

959 iron-restricted conditions. (A) Enumeration of PADP6 from $48 \mathrm{~h}$ single-species

960 macrocolonies grown in media supplemented without and with increasing 22D

961 concentrations (2, 3 and $4 \mathrm{mM}$ ), which is then further supplemented without and with

962 lactic acid (10 and $20 \mathrm{mM}$ ). Dotted lines represent inoculum of bacteria spotted. $\mathrm{N} \geq 3$

963 with 3 technical replicates; error bars represent SD from the mean. Statistical analysis

964 was performed using Mann-Whitney $U$ test, ${ }^{*} p<0.05,{ }^{* *} p<0.01,{ }^{* * *} p<0.001,{ }^{* * * *} p$

$965<0.0001$. (B) Enumeration of PADP6 from $48 \mathrm{~h}$ single-species macrocolonies grown

966 in $2 \mathrm{mM}$ 22D-chelated media supplemented without and with $20 \mathrm{mM}$ lactic acid (pH

967 unadjusted and $\mathrm{pH}$ adjusted to $\mathrm{pH}$ 6.6) or $20 \mathrm{mM}$ citric acid (pH unadjusted and $\mathrm{pH}$

968 adjusted to $\mathrm{pH}$ 6.61). Dotted lines represent inoculum of bacteria spotted and dashed

969 lines represent limit of detection. $\mathrm{N}=3$ with 3 technical replicates; error bars represent

970 SD from the mean. Statistical analysis was performed using Mann-Whitney U test, ${ }^{*} p$

$971<0.05,{ }^{* *} p<0.01,{ }^{* * *} p<0.001,{ }^{* * * *} p<0.0001$. 
A

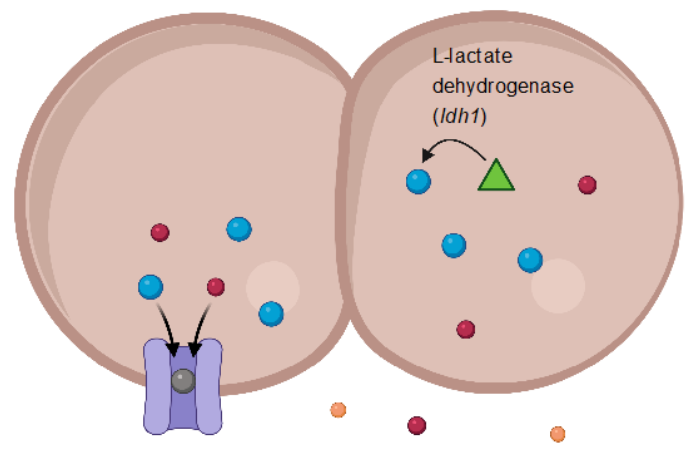

-

-

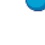

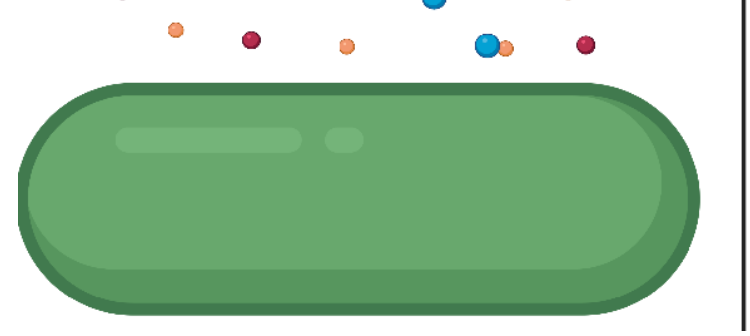

B

Iron-restricted conditions
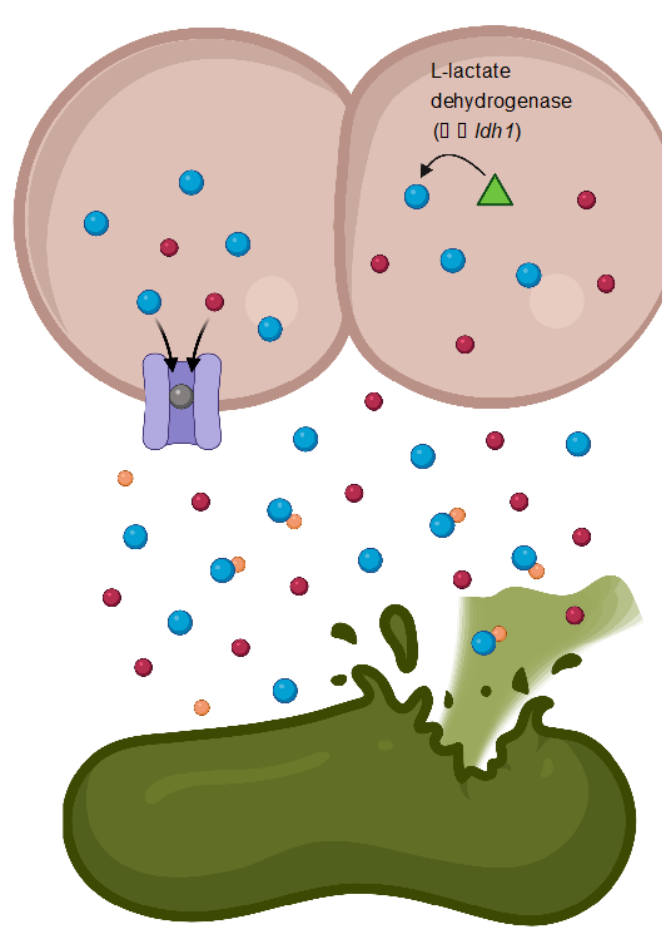

E. faecalis

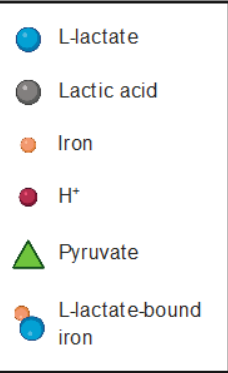

P. aeruginosa

Figure 4 Proposed working model of $E$. faecalis and $P$. aeruginosa in vitro polymicrobial interactions. Interactions between $E$. faecalis and $P$. aeruginosa in $(A)$ unchelated and $(B)$ iron-restricted conditions. $(A)$ In unchelated conditions, L-lactate produced in E. faecalis is exported with hydrogen ions via a symporter (purple) as lactic acid, which is then deprotonated in the environment into L-lactate and hydrogen ions $\left(\mathrm{H}^{+}\right)$. These L-lactate then chelates iron in the environment. (B) In iron-restricted conditions, $E$. faecalis Idh1 expression is upregulated. Consequently, as $E$. faecalis grows, L-lactate production and lactic acid secretion increases. This further chelates iron in an iron-restricted conditions and lowers the environmental $\mathrm{pH}$ to a point that $P$. aeruginosa could not grow in. 
Table 1 E. faecalis L-lactate dehydrogenase differentially regulated in iron-restricted conditions.

981

\begin{tabular}{|c|c|c|c|c|c|c|}
\hline Comparison conditions & Locus tag & Name & Description & $\log 2 F C$ & p-value & FDR \\
\hline $\begin{array}{l}\text { OG1RF single-species macrocolonies } \\
\text { grown in iron restriction relative to OG1RF } \\
\text { single-species macrocolonies grown in } \\
\text { unchelated conditions }\end{array}$ & OG1RF_10199 & ldh1 & $\begin{array}{l}\text { L-lactate } \\
\text { dehydrogenase }\end{array}$ & 0.57 & 8.75E-05 & $1.68 \mathrm{E}-03$ \\
\hline $\begin{array}{l}\text { Mixed OG1RF and PADP6 macrocolonies } \\
\text { grown in iron restriction relative to mixed } \\
\text { OG1RF and PADP6 macrocolonies grown in } \\
\text { unchelated conditions }\end{array}$ & OG1RF_10199 & Idh1 & $\begin{array}{l}\text { L-lactate } \\
\text { dehydrogenase }\end{array}$ & 3.27 & $9.02 \mathrm{E}-25$ & 8.91E-24 \\
\hline
\end{tabular}




\section{A}
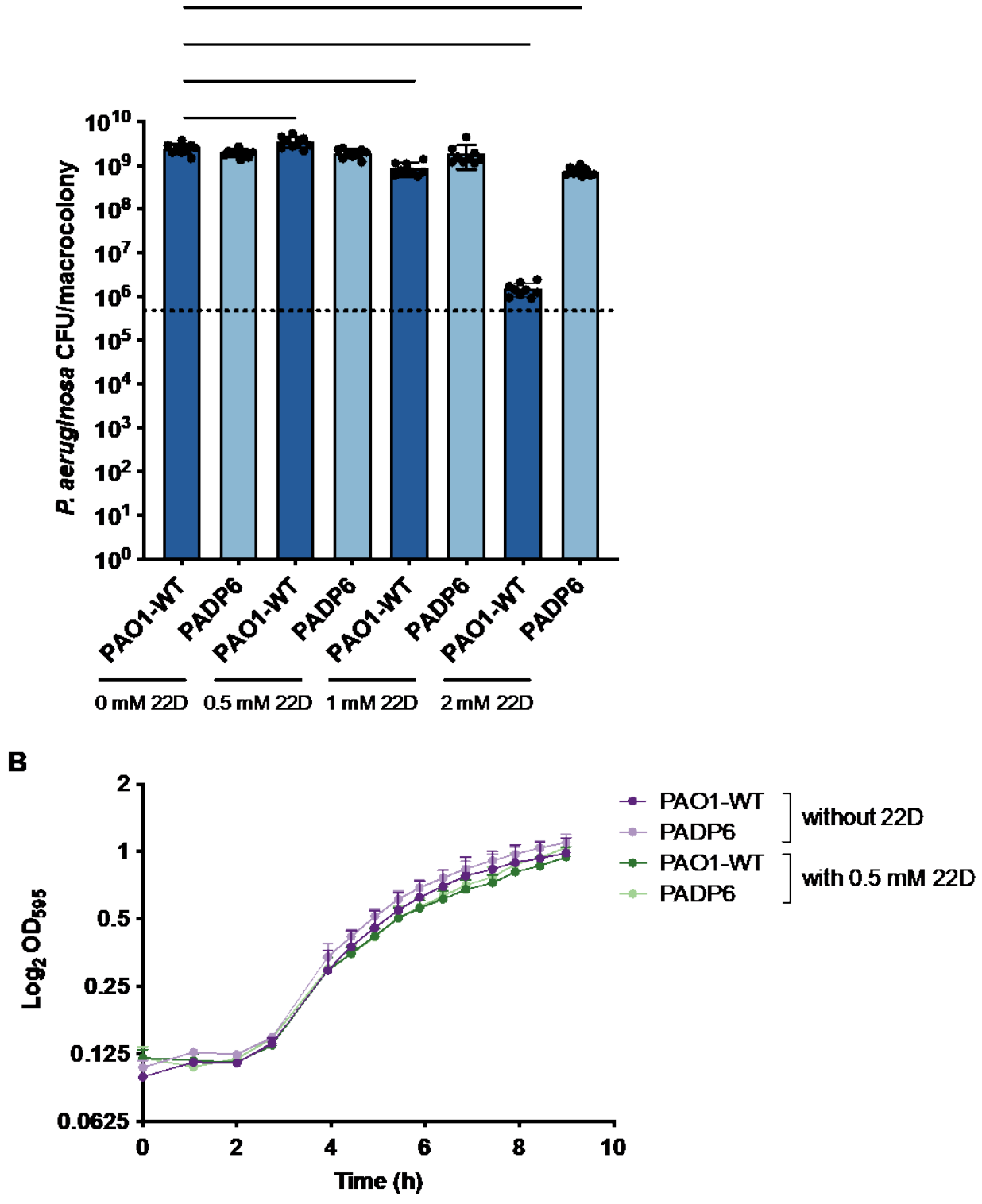

984 Supplementary Figure $1 P$. aeruginosa growth responses to iron restriction. (A)

985 Enumeration of PAO1-WT and PADP6 from $24 \mathrm{~h}$ single-species macrocolonies grown

986 in media supplemented without and with increasing 22D concentrations $(0.5,1$ and 2

$987 \mathrm{mM}$ ). Dotted lines represent inoculum of bacteria spotted. $\mathrm{N}=3$ with 3 technical

988 replicates; error bars represent SD from the mean. Statistical analysis was performed

989 using Mann-Whitney $U$ test, ${ }^{*} p<0.05$, ${ }^{* *} p<0.01,{ }^{* * *} p<0.001,{ }^{* * *} p<0.0001$. (B)

990 Planktonic growth of PAO1-WT and PADP6 in TSBG media supplemented without

991 and with $0.5 \mathrm{mM} 22 \mathrm{D} . \mathrm{N}=3$ with 3 technical replicates; error bars represent SD from 992 the mean. 
A

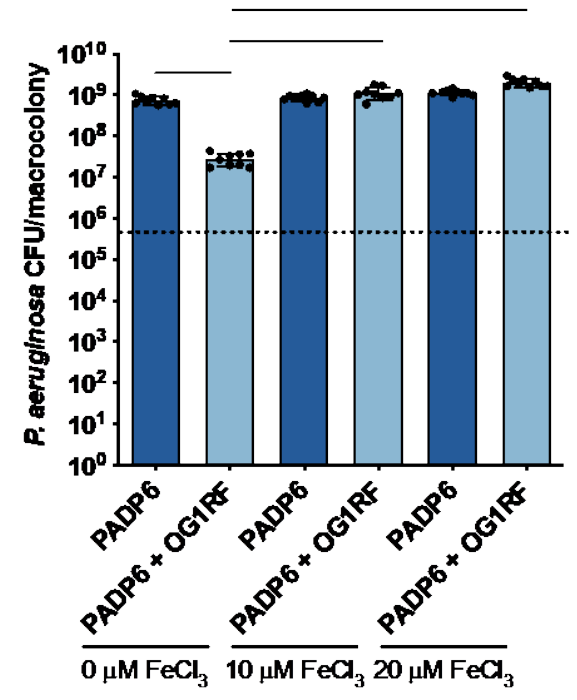

C

Single-species

Mixed with OG1RF

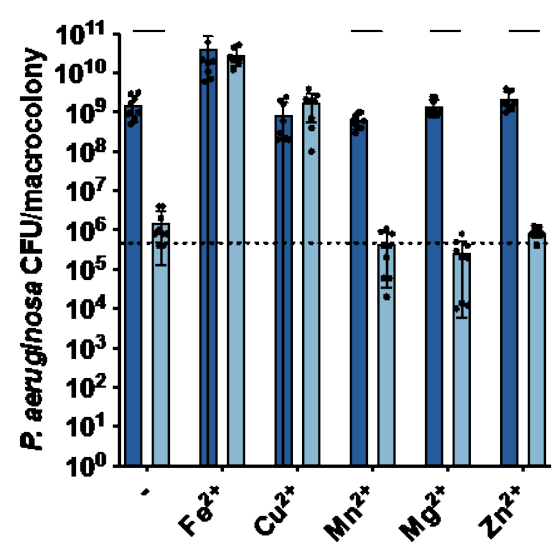

$\mathbf{B}$

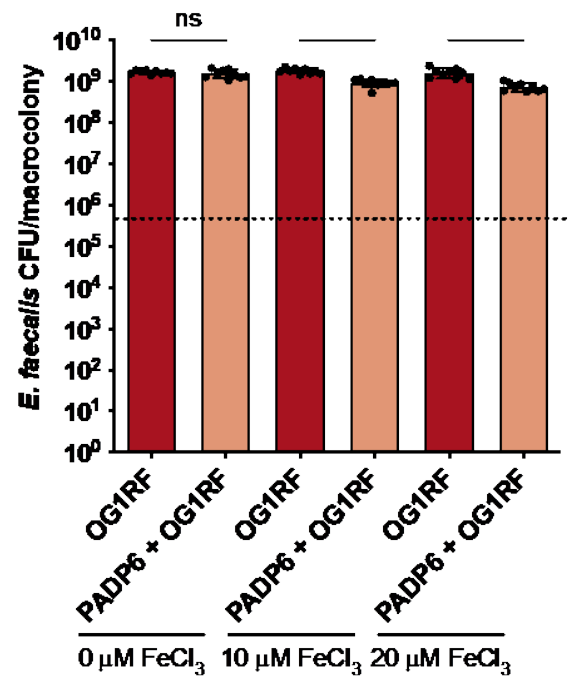

D

$\square$ Single-species

Mixed with PAO1 BAA-47

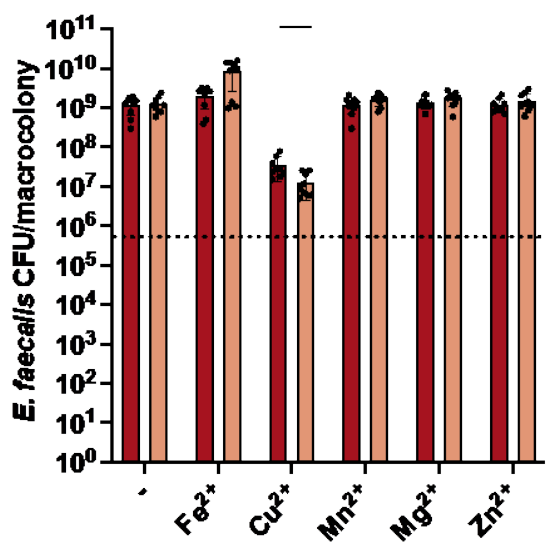

Supplementary Figure 2 Growth inhibition of $P$. aeruginosa by $E$. faecalis is ironspecific. Enumeration of (A) PADP6 and (B) OG1RF from $24 \mathrm{~h}$ macrocolonies with single or mixed inoculums grown in $2 \mathrm{mM}$ 22D-chelated media without and with $\mathrm{FeCl}_{3}$ (10 and $20 \mu \mathrm{M})$. Bacterial species were mixed at a 1:1 ratio for mixed-species macrocolonies. Dotted lines represent inoculum of bacteria spotted. $N=3$ with 3 technical replicates; error bars represent SD from the mean. Statistical analysis was performed using Mann-Whitney $U$ test, ${ }^{*} p<0.05,{ }^{* *} p<0.01,{ }^{* *} p<0.001,{ }^{* * * *} p<$ 0.0001. Enumeration of (C) PAO1 BAA-47 and (D) OG1RF from $24 \mathrm{~h}$ single- and mixed-species macrocolonies grown in $1 \mathrm{mM} 22 \mathrm{D}$-chelated media without and with $100 \mu \mathrm{M}$ of varying trace metals. Bacterial species were mixed at a 1:1 ratio for mixedspecies macrocolonies. Dotted lines represent inoculum of bacteria spotted. $\mathrm{N}=3$ with 3 technical replicates; error bars represent SD from the mean. Statistical analysis was 
bioRxiv preprint doi: https://doi.org/10.1101/2022.01.18.476859; this version posted January 20,2022 . The copyright holder for this preprint (which was not certified by peer review) is the author/funder, who has granted bioRxiv a license to display the preprint in perpetuity. It is made available under aCC-BY-NC-ND 4.0 International license.

1006 performed using Mann-Whitney U test, ${ }^{*} p<0.05,{ }^{* *} p<0.01,{ }^{* * *} p<0.001,{ }^{* * *} p<$ $1007 \quad 0.0001$. 
A

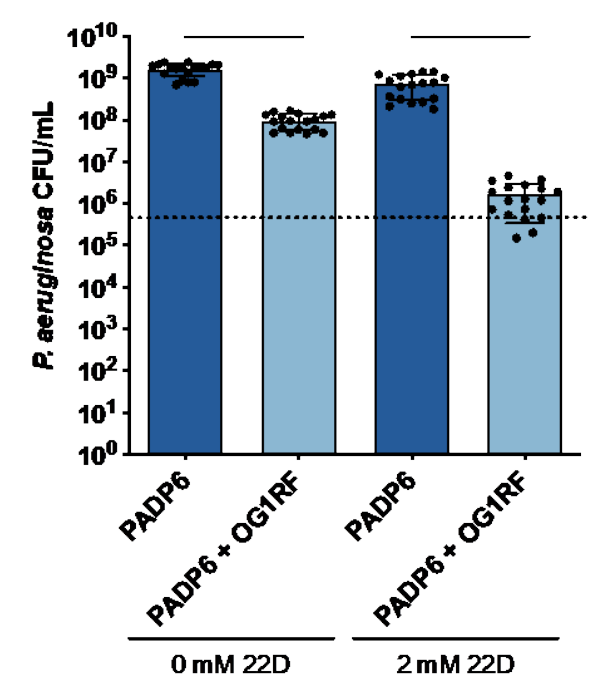

B

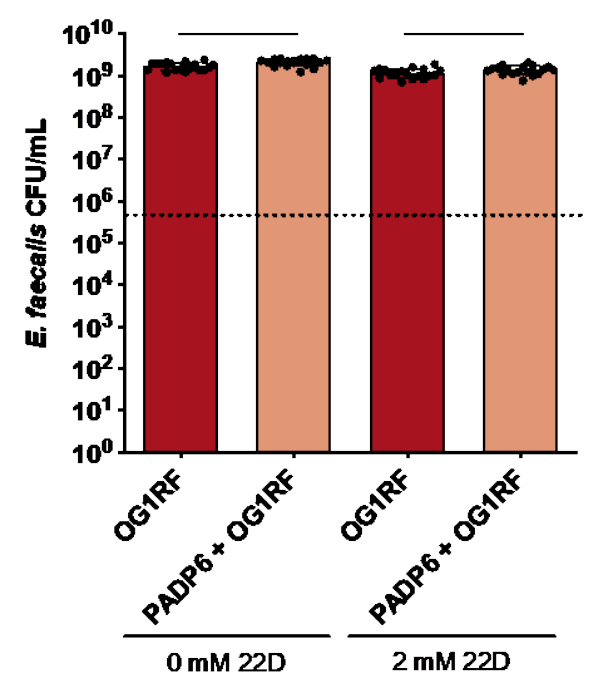

1009 Supplementary Figure $3 \boldsymbol{E}$. faecalis inhibits $\boldsymbol{P}$. aeruginosa growth in planktonic

1010 conditions regardless of iron levels. Enumeration of (A) PADP6 and (B) OG1RF

1011 from single or mixed inoculums grown for $24 \mathrm{~h}$ in media supplemented without and

1012 with $2 \mathrm{mM}$ 22D. Bacterial species were mixed at a 1:1 ratio for mixed-species

1013 macrocolonies. Dotted lines represent inoculum of bacteria spotted. $\mathrm{N} \geq 3$ with 3

1014 technical replicates; error bars represent SD from the mean. Statistical analysis was

1015 performed using Mann-Whitney U test, ${ }^{*} p<0.05$, ${ }^{* *} p<0.01,{ }^{* * *} p<0.001$, ${ }^{* * * *} p<$ 10160.0001. 
A

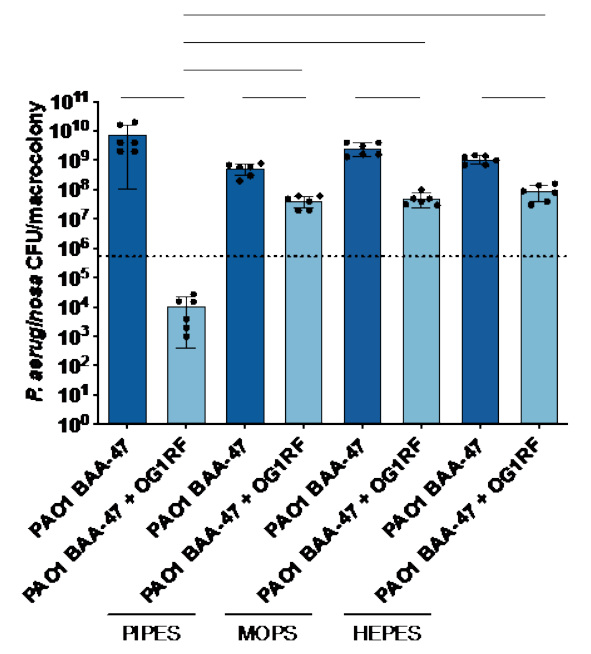

c

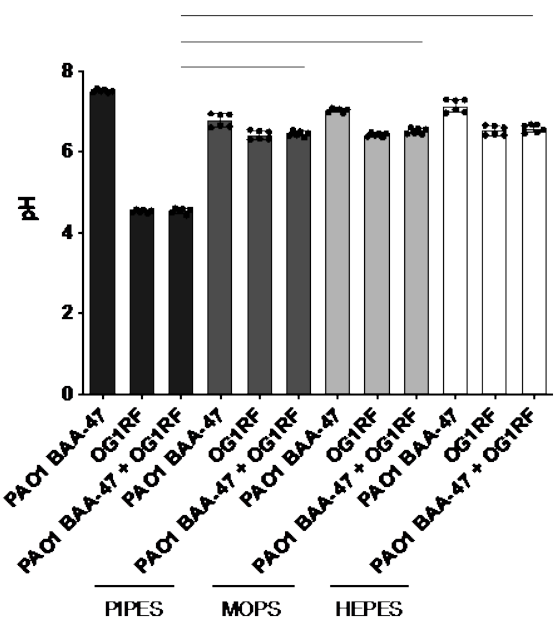
$* * * * p<0.0001$
B

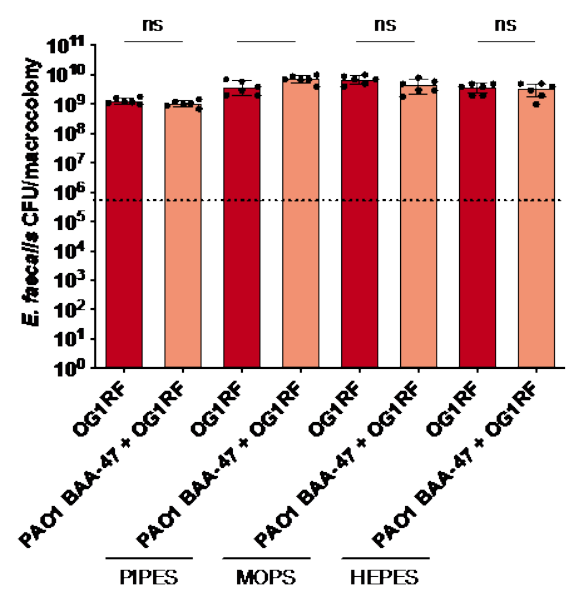

\section{Supplementary Figure 4 Alleviating pH acidification using buffered media} partially rescues $\boldsymbol{P}$. aeruginosa growth inhibition in iron-restricted conditions. Enumeration of (A) PAO1 BAA-47 and (B) OG1RF from single- and mixed-species macrocolonies grown for $24 \mathrm{~h}$ in media supplemented with $1 \mathrm{mM} 22 \mathrm{D}$ and either 200 mM PIPES, MOPS or HEPES buffer. Bacterial species were mixed at a 1:1 ratio for mixed-species macrocolonies. Dotted lines represent inoculum of bacteria spotted. $\mathrm{N}$ = 2 with 3 technical replicates; error bars represent SD from the mean. Statistical analysis was performed using Mann-Whitney $U$ test, ${ }^{*} p<0.05$, ${ }^{* *} p<0.01,{ }^{* * *} p<0.001$, ${ }^{* * * *} p<0.0001$. (C) The corresponding $\mathrm{pH}$ quantification of single- and mixed-species macrocolonies in (A) and (B). Error bars represent SD from the mean. Statistical analysis was performed using Mann-Whitney $U$ test, ${ }^{*} p<0.05,{ }^{* *} p<0.01,{ }^{* * *} p<0.001$, 
1030 Supplementary Table 1 E. faecalis transposon mutants identified from transposon

1031 library screen with PADP6 in iron-restricted conditions.

1032

1033

\begin{tabular}{lll}
\hline Locus tag & Name & Description \\
\hline OG1RF_10199 & Idh1 & L-lactate dehydrogenase \\
OG1RF_10480 & gloA3 & Lactoylglutathione lyase \\
OG1RF_12538 & guaB & IMP dehydrogenase \\
\hline
\end{tabular}


1034 Supplementary Table 2 Selected $P$. aeruginosa raw counts of iron acquisition genes from mixed PADP6 and OG1RF 1035 macrocolonies and mixed PADP6 + OG1RF $\Delta / d h 1$ macrocolonies in iron-restricted conditions.

1036

\begin{tabular}{lllllclc}
\hline Locus tag & Name & \multicolumn{3}{c}{ PADP6 + OG1RF } & \multicolumn{3}{c}{ PADP6 + OG1RF $\Delta$ ldh1 } \\
\hline PA2386 & $p v d A$ & 0 & 3 & 0 & 102 & 68 & 46 \\
PA4228 & $p c h D$ & 0 & 2 & 0 & 79 & 42 & 33 \\
PA2399 & $p v d D$ & 0 & 2 & 0 & 146 & 95 & 54 \\
PA2424 & $p v d L$ & 0 & 1 & 0 & 56 & 68 & 64 \\
PA4221 & $f p t A$ & 1 & 0 & 0 & 134 & 72 & 62 \\
& & & & & & & \\
Total P. aeruginosa raw counts & & 1005 & 191602 & 1362 & 217172 & 192025 & 172212 \\
Total E. faecalis raw counts & & 258404 & 243639 & 260881 & 881980 & 733793 & 764946 \\
Percentage of $P$. aeruginosa raw counts (\%) & 0.39 & 44.02 & 0.52 & 19.76 & 20.74 & 18.38 \\
\hline
\end{tabular}


1038 Supplementary Table 3 E. faecalis iron acquisition genes upregulated in PADP6 + OG1RF macrocolonies relative to PADP6 +

1039 OG1RF $\Delta / d h 1$ macrocolonies grown in iron-restricted conditions.

1040

Upregulated in PADP6 + OG1RF macrocolonies grown in iron-restricted conditions

\begin{tabular}{|c|c|c|c|c|c|}
\hline Locus tag & Name & Description & $\log 2 \mathrm{FC}$ & p-value & FDR \\
\hline OG1RF_11917 & metl & ABC transporter permease & 4.39 & 1.07E-06 & 7.70E-06 \\
\hline OG1RF_11762 & & $\mathrm{ABC}$ transporter permease & 3.33 & $1.04 \mathrm{E}-10$ & $1.55 \mathrm{E}-09$ \\
\hline OG1RF_10136 & & Ferrichrome $A B C$ transporter substrate-binding protein & 2.03 & $1.74 \mathrm{E}-05$ & 9.86E-05 \\
\hline OG1RF_12352 & & Iron $\mathrm{ABC}$ transporter ATP-binding protein & 1.86 & $9.35 \mathrm{E}-05$ & 4.60E-04 \\
\hline OG1RF_12351 & & Iron $\mathrm{ABC}$ transporter substrate-binding protein & 1.75 & 2.11E-04 & 9.47E-04 \\
\hline OG1RF_12353 & & Iron $\mathrm{ABC}$ transporter permease & 1.73 & 3.16E-04 & 1.37E-03 \\
\hline OG1RF_10360 & feoB & Ferrous iron transport protein $B$ & 1.64 & 1.47E-04 & 6.97E-04 \\
\hline OG1RF_10128 & & $\mathrm{ABC}$ transporter permease & 1.51 & 1.77E-03 & 5.99E-03 \\
\hline OG1RF_12354 & & Iron $\mathrm{ABC}$ transporter permease & 1.50 & 9.31E-04 & $3.48 \mathrm{E}-03$ \\
\hline
\end{tabular}


1042 Supplementary Table 4 Bacterial strains used in this study.

1043

\begin{tabular}{|c|c|}
\hline Strain & Reference \\
\hline \multicolumn{2}{|l|}{ P. aeruginosa } \\
\hline PAO1 WT & $(100)$ \\
\hline PADP6 & This study \\
\hline PADP6-mCherry & This study \\
\hline PAO1 BAA-47 & (101) \\
\hline PR1 & (101) \\
\hline PR2 & (101) \\
\hline PR30 & (101) \\
\hline PR80 & (101) \\
\hline PR82PR101 & (101) \\
\hline PR305 & (101) \\
\hline PR325 & (101) \\
\hline \multicolumn{2}{|l|}{ E. faecalis } \\
\hline OG1RF & $(102)$ \\
\hline OG1RF $\Delta / d h 1$ & This study \\
\hline OG1RF $\Delta / d h 1:: / d h 1$ & This study \\
\hline DS16 MG1505 ST40 & $(103)$ \\
\hline Merz 192 MG1519 ST40 & (103) \\
\hline WH257 MG1422 ST9 & (103) \\
\hline WH571 MH1424 ST9 & (103) \\
\hline SF26630 MG1556 ST6 & (103) \\
\hline V583MG899 ST6 & (103) \\
\hline T13 MG1344 ST21 & (103) \\
\hline SF24396 MG1544 ST21 & (103) \\
\hline UAA1014 MG2962 ST23 & PRJNA88811 \\
\hline B84847 MG3030 ST23 & $(104)$ \\
\hline SF21521 MG1542 ST28 & (103) \\
\hline B56765 MG3031 ST28 & (104) \\
\hline \multicolumn{2}{|l|}{ E. coli } \\
\hline E. coli pTNS1 & (93) \\
\hline E. coli pUC18-miniTn7-P tac-mCherry & (105) \\
\hline
\end{tabular}

1044 


\section{Supplementary Table 5 Primers used in this study.}

1046

\begin{tabular}{|c|c|c|}
\hline Primer name & Sequence (5' to 3') & Reference \\
\hline 1-Idh1_UpF & $\begin{array}{l}\text { TGTGTGATGGATATCTGCACGGACCAACAG } \\
\text { AGCGACCTGATTC }\end{array}$ & This study \\
\hline 2-Idh1_UpR & $\begin{array}{l}\text { GTGTACCATTCCTTCCTCTACATTCTTTTTCG } \\
\text { TG }\end{array}$ & This study \\
\hline 3-Idh1_DownF & $\begin{array}{l}\text { TAGAGGAAGGAATGGTACACAACTCCTTCTA } \\
\text { TAATAGTCGAAAATTAAAAACAACCA }\end{array}$ & This study \\
\hline 4-Idh1_DownR & $\begin{array}{l}\text { AGTGTGCTGGAATTCTGCATAGCGAATGGTA } \\
\text { CGAATACAATGTGTGTG }\end{array}$ & This study \\
\hline COM_ldh1_F & $\begin{array}{l}\text { CTGAGCGGCCGCTTTGTAAAGCGCCTGCCA } \\
\text { TC }\end{array}$ & This study \\
\hline COM_ldh1_R & ACTGGGATCCGTGAACGTTGGTTTCCCGTG & This study \\
\hline
\end{tabular}

